\title{
A Comparison of Enhancement Techniques for Footwear Impressions on Dark and
}

\section{Patterned Fabrics}

Kevin J. Farrugia, ${ }^{1,2}$ Ph.D.; Helen Bandey, ${ }^{3}$ Ph.D.; and Niamh Nic Daéid, ${ }^{1}$ Ph.D.

${ }^{1}$ Centre for Forensic Science, WestCHEM, Department of Pure and Applied Chemistry, University of Strathclyde, Glasgow, G1 1XW, UK

${ }^{2}$ School of Contemporary Sciences, Division of Forensic and Bio Sciences, University of Abertay, Bell Street, Dundee, DD1 1HG, UK

${ }^{3}$ Centre for Applied Science and Technology (CAST, formerly HOSDB), Home Office Science, Woodcock Hill, Sandridge, St. Albans, AL4 9HQ, UK

\section{Source of Funding}

Financial support provided by the Home Office Centre for Applied Science and Technology (CAST), the Engineering and Physical Sciences Research Council (EPSRC) and the University of Strathclyde. This work is also partially funded by the Malta Government Scholarship Scheme.

All work was carried out at the University of Strathclyde.

No conflicts of interest.

Parts of this work were presented at the $95^{\text {th }}$ Annual International Association of Identification (IAI) Conference in Spokane, Washington, USA (July, 2010). 


\section{ABSTRACT}

The use of chemical enhancement techniques on porous substrates, such as fabrics, poses several challenges predominantly due to the occurrence of background staining and diffusion as well as visualisation difficulties. A range of readily available chemical and lighting techniques were utilised to enhance footwear impressions made in blood, soil and urine on dark and patterned fabrics. Footwear impressions were all prepared at a set force using a specifically built footwear rig. In most cases, results demonstrated that fluorescent chemical techniques were required for visualisation as non-fluorescent techniques provided little or no contrast with the background. Occasionally this contrast was improved by oblique lighting. Successful results were obtained for the enhancement of footwear impressions in blood, however the enhancement of footwear impressions in urine and soil on dark and patterned fabrics was much more limited. The results demonstrate that visualisation and fluorescent enhancement on porous substrates such as fabrics is possible.

Keywords: forensic science, footwear impression, shoeprint, enhancement, fabric, blood, urine, soil 
Techniques such as ninhydrin and 1,8-diazafluoren-9-one (DFO) have been developed for treating impressions on porous substrates, however such techniques are designed more for substrates such as paper rather than fabric surfaces and as such the choice of techniques might be limited. Previous publications for the enhancement of impressions on fabric have generally been limited to casework examples (1-3) however, more recently, research has been devoted for the enhancement of impressions on fabric by means of both physical and chemical techniques (4-15). The enhancement of such impressions is difficult, often due to extensive background staining that can occur. Most research has focused on the enhancement of footwear impressions in blood and mud as these contaminants might be encountered to a greater extent at crime scenes (16-18) though other contaminants (oil based lubricants (WD40), milk, beer, baby oil and soft drinks), have also been examined (19).

The use of gelatin lifters can improve the contrast with the background and has been suggested for lifting impressions in blood after treating with protein stains $(20,21)$. Furthermore, impressions in blood enhanced with acid violet 19 and lifted with a white gelatin lifter may fluoresce when illuminated with a green excitation source (515 to $560 \mathrm{~nm}$ ). The advantages of the fluorescent protein stain acid yellow 7 (AY7) as a cheap, straight forward enhancement technique for impressions in blood has been put forward $(22,23)$ and a recent study (24) comparing phloxine B and acid yellow 7 (water/ethanol/acetic acid formulation) concluded that in most cases, AY7 provided better results due to fluorescence facilitating the suppression of background contrast issues. A comparison of AY7, acid black 1 and white small particle reagent for the enhancement of impressions in blood on black non porous surfaces also highlighted the advantages of AY7 (25). Other suitable techniques include the heme reactive reagents (peroxidase reagents) such as leuco crystal violet (LCV), fluorescein and luminol (26-30) and the amino acid reactive reagents such as ninhydrin, 1,8diazafluoren-9-one (DFO) and 1,2-indanedione (1,2-IND) (16). Recently, the use of leuco 
rhodamine $6 \mathrm{G}$, prepared from the reduction of rhodamine $6 \mathrm{G}$ over zinc, has been suggested for the enhancement of latent fingerprints in blood (31). Chemicals such as diaminobenzidine (DAB) and merbromin are not recommended due to their potential carcinogenic nature (28, 32). Furthermore, DAB requires a phosphate buffer solution and a stock solution which needs to be kept at $-20^{\circ} \mathrm{C}$ until just prior to use (33). Research by Bergeron (34) illustrated a titanium dioxide method for developing impressions in blood on dark surfaces, however, poor results were reported for impressions in blood on porous surfaces. Alginate impression materials, commonly used in dentistry (35) have also been evaluated for lifting impressions in blood from fabrics with successful results $(7,10,36)$.

A variety of techniques have been reported for the enhancement of footwear impression in dust or soil which target iron, calcium and other metals. The most commonly reported reagents include ammonium thiocyanate $(37,38)$, bromophenol blue $(5,39)$ and potassium ferrocyanide (40) and successful enhancement has been demonstrated to be dependant on the area where the soil or dust was recovered from (14). The enhancement of impressions in urine by traditional enhancement techniques such as alternative lighting and amino acid reacting techniques is limited $(13,41)$.

This work compares the use of a wide range of enhancement techniques for the enhancement of impressions in blood, urine and mud on dark and patterned fabrics. 


\section{Materials and Methods}

Deposition of the footwear impressions and preparation of the test marks

Footwear impressions in blood (bovine), soil and urine were prepared where a constant force was used to apply the footwear to the fabric in each case as described elsewhere $(10-14,42)$. A urine sample was collected from a male donor and soil samples were collected from four different regions in Scotland, U.K. Six repeat impressions for each fabric-enhancement technique were prepared and each impression was aged for 7 days before enhancement. A diminishing series was also employed to test the sensitivity of the technique on the particular substrate. Photography at various stages of preparation and enhancement of the impression was performed using a Canon EOS 300D [sensor size 22.7 x $15.1 \mathrm{~mm}\left(3.42 \mathrm{~cm}^{2}\right)$ ]. Appropriate controls and calibration of camera and computer monitor were also carried out to ensure the reliability of the experiments.

\section{Fabrics}

Table 1 presents the fabrics utilised in the study. Brown bovine leather was used for preparing footwear impressions in blood and urine only whereas leatherette was used for the preparation of footwear impressions in soil only. 
Table 1 - Fabrics utilised in the study

\begin{tabular}{|c|c|}
\hline Fabric & Supplier \\
\hline Black Cotton [CD13D] & WBL Whaleys Bradford Ltd. \\
Plain weave; 19 warp threads/cm; 10 weft threads/cm & \\
\hline Black Polyester Taffeta [SF25A] & WBL Whaleys Bradford Ltd. \\
\hline Black Nylon (82\%) / Lycra (18\%) [SF27] & WBL Whaleys Bradford Ltd. \\
\hline Patterned Cotton [SF2360/B] & WBL Whaleys Bradford Ltd. \\
Twill weave; 19 warp threads/cm; 19 weft threads/cm & Mandors, Glasgow, UK \\
\hline Blue Denim [Rialto Indigo] & \\
\hline Bwill weave; 25 warp threads/cm; 19 weft threads/cm & The Clyde Leather Co., Glasgow, \\
\hline Plain Dyed Brown Leatherette & UK \\
\hline KBT259 (C2708) (68) (F10) & www.fabricuk.com \\
\hline
\end{tabular}

\section{Blood Enhancement Techniques}

\section{Protein Stains}

All protein stains were prepared using a water/ethanol/acetic acid solvent system (43). The impressions in blood were fixed by immersion in a solution of $2 \%$-sulfosalicylic acid (Acros) for a minimum period of 5 minutes. Following the fixation procedure, the impressions were immersed for a minimum period of 10 minutes in a solution of the appropriate protein stain $(1 \mathrm{~g})$ in acetic acid $(50 \mathrm{~mL}$, Sigma), ethanol (250mL, Sigma) and distilled water $(700 \mathrm{~mL})$ before rinsing in a de-staining solution of acetic acid, ethanol and distilled water. The protein stains used in this study were acid black 1, acid violet 17 and acid yellow 7 (as recommended for the enhancement of fingerprints in blood in the Manual of Fingerprint Development Techniques) as well as acid violet 19. 
Heme Reagents

LCV formulation

5-sulphosalicyclic acid dihydrate (10g, Acros) was dissolved in 3\% hydrogen peroxide (500mL, VWR). Sodium acetate (3.7g, Sigma) was added to the mixture followed by leuco crystal violet (1g, Sigma) and stirred using a magnetic stirrer until completely dissolved. The reagent was applied by spraying with an Ecospray ${ }^{\circledR}$ supplied by Bluestar ${ }^{\circledR}$ Forensic.

\section{LMG formulation}

Leucomalachite green $(0.2 \mathrm{~g}, \mathrm{BDH})$ was dissolved in methanol $(67 \mathrm{~mL}$, Sigma) followed by the addition of glacial acetic acid (33mL, Sigma), sodium perborate $(0.67 \mathrm{~g}$, Sigma) and HFE $7100(300 \mathrm{~mL}, 3 \mathrm{M}$ Novec) with constant stirring. The resulting solution was applied by spraying with a Preval ${ }^{\circledR}$ sprayer.

\section{Leuco Rhodamine 6G (LR6G)}

Stock solution: Rhodamine 6G (1g, Acros), powdered zinc (20g, Acros) and glacial acetic acid (10mL, Sigma) were added to ethanol (200mL, Sigma) and stirred with a magnetic stirrer until dissolved (with the exception of zinc). This reduction reaction was then continued for 30 minutes followed by the addition of 5-sulfosalicylic acid (0.22g, Acros) and mossy zinc (10g, Acros). The cooled solution was then decanted carefully to remove the zinc which was neutralised prior to disposal.

Working solution: LR6G stock solution $(20 \mathrm{~mL})$ was added to diethyl ether (80mL) (Sigma) followed by the addition of 3\% hydrogen peroxide (8-10 drops) (VWR) and further stirring. The solution was then applied by spraying with an Ecospray ${ }^{\circledR}$. 


\section{Fluorescein}

Solution A: A $10 \% \mathrm{NaOH}$ solution was prepared before dissolving fluorescein (1g, Sigma) $100 \mathrm{~mL}$ of this solution. Zinc powder (10g, Sigma) was added and the solution brought to a gentle boil. The cooled solution was then decanted carefully to remove the zinc which was neutralised prior to disposal. A 1:20 ratio of this solution with distilled water was then prepared.

Solution B: A $10 \% \mathrm{H}_{2} \mathrm{O}_{2}$ solution (VWR) was prepared by adding $30 \% \mathrm{H}_{2} \mathrm{O}_{2}(100 \mathrm{~mL}$ ) to distilled water $(200 \mathrm{~mL})$. The reagents were applied by spraying solution A followed by solution B using an Ecospray ${ }^{\circledR}$ unit supplied by Bluestar ${ }^{\circledR}$ Forensic.

\section{Hemascein $^{\circledR}$}

Stock solution: Distilled water $(5 \mathrm{~mL})$ was added to the Hemascein ${ }^{\circledR}$ powder vial and mixed vigorously.

Working solution: The stock solution $(1 \mathrm{~mL})$ was diluted with distilled water $(100 \mathrm{~mL})$ in one of the ABAspray ${ }^{\circledR}$ supplied. 1-3\% hydrogen peroxide was also prepared in another sprayer. The reagents were sprayed using ABAspray ${ }^{\circledR}$ to lightly mist the target area with the working solution followed by the hydrogen peroxide solution.

\section{Luminol}

The luminol formulation utilised in this study was Bluestar ${ }^{\circledR}$ Forensic Magnum from Bluestar ${ }^{\circledR}$ Forensic. It was prepared by dissolving the three tablets in the liquid supplied $(125 \mathrm{~mL})$ and then applied using an Ecospray ${ }^{\circledR}$ unit supplied by Bluestar ${ }^{\circledR}$ Forensic. Photography of the resultant chemiluminescent reactions was obtained with settings set at ISO400, f 5.6, exposure of 15 seconds and white balance set on tungsten. 
Other Reagents

GC Aroma Dust Fine III

Nine scoops (using a supplied scoop) of powder were added to water (200mL) with immediate stirring for 30 seconds. The resultant paste was applied to the impression with a large plastic spatula. Pressure was lightly and evenly applied across its surface and the alginate removed after 1 minute. The cast was allowed to dry completely overnight before treating with acid black 1 .

\section{Titanium Dioxide}

Titanium dioxide (1g, Sigma) was dissolved in methanol (10mL, Sigma) and sprayed onto the impression with an Ecosprayer ${ }^{\circledR}$ followed by rinsing with methanol (20mL, Sigma).

Urine Enhancement Techniques

Amino Acid Stains(43, 44).

Ninhydrin

Concentrated Solution: ninhydrin (25g, Sigma) was dissolved in absolute ethanol $(225 \mathrm{~mL})$

(Sigma) followed by the addition of ethyl acetate $(10 \mathrm{~mL}$, Sigma) and acetic acid $(25 \mathrm{~mL}$, Sigma).

Ninhydrin Working Solution: ninhydrin concentrated solution $(52 \mathrm{~mL})$ was diluted in HFE 7100 (1L, 3M Novec) whilst stirring with a magnetic stirrer. 
DFO

Working Solution: DFO (0.25g, BVDA) was dissolved in methanol (30mL, Sigma) followed by the addition of acetic acid (20mL, Sigma), HFE71DE (275mL, 3M Novec) and HFE7100 (725mL, 3M Novec) with continued stirring.

\section{1,2-Indanedione}

Working Solution: 1,2-indanedione (0.25g, BVDA) was dissolved in ethyl acetate $(90 \mathrm{~mL}$, Sigma), acetic acid (10mL, Sigma), $\mathrm{ZnCl}_{2}$ stock solution $(0.5 \mathrm{~mL})$ before HFE-7100 (1L, 3M Novec) was added to the mixture and stirred.

Treatment of articles with ninhydrin, DFO and 1,2-Indanedione: The articles were immersed in the working solution for a maximum of five seconds and allowed to dry completely before heating in a humidifying oven $(65 \%)$ at $80^{\circ} \mathrm{C}$ for 4 minutes (ninhydrin) or in a dry oven at $100^{\circ} \mathrm{C}$ for 20 minutes (DFO) and 10 minutes (1,2-indanedione).

\section{DMAC}

Pre-impregnated DMAC sheets: DMAC (Acros, 0.25g) was dissolved in ethanol (Sigma, $100 \mathrm{~mL}$ ) and poured into a dipping tray. White A4 sheets of copier paper were soaked in the solution and left to dry in a fume hood

Treatment of articles: The articles to be treated were placed between two sheets of paper preimpregnated with DMAC such that a pre-impregnated DMAC sheet was placed between each article and then finally wrapped in two sheets of aluminium foil. The layers were then left in a press overnight. 


\section{Soil Enhancement Techniques}

Controlled spraying was essential to avoid diffusion and blasting of the original impression.

Potassium Thiocyanate formulation: potassium thiocyanate (15g, Sigma) was dissolved in distilled water $(15 \mathrm{~mL})$ and acetone $(120 \mathrm{~mL}$, Sigma) and stirred thoroughly. Dilute sulphuric acid $(8.5 \mathrm{~mL}$, Sigma) was added slowly to produce a milky mixture which eventually separated in two layers and the top, clear layer was utilised.

Treatment of articles: The reagents were lightly sprayed over the impression using the Ecospray ${ }^{\circledR}$.

Potassium Ferrocyanide formulation:

Solution A: hydrochloric acid (10mL, Sigma) and ethanol (90mL, Sigma).

Solution B: potassium ferrocyanide (5g, Acros) dissolved in distilled water (100mL).

Treatment of articles: The articles were sprayed lightly with Solution A using the Ecospray ${ }^{\circledR}$ and allowed to stand for 10-20 seconds. Then, while the sprayed area was still damp, the article was lightly sprayed with solution B.

Ammonium pyrrolidinedithiocarbamate formulation:

Solution A: hydrochloric acid (1mL, Sigma) and ethanol (9mL, Sigma).

Solution B: ammonium pyrrolidinedithiocarbamate (1g, Acros) and sodium citrate (3g, Sigma) were dissolved in ethanol (50mL, Sigma) and distilled water (50mL).

Treatment of articles: The articles were sprayed lightly with solution A using the Ecospray ${ }^{\circledR}$ and allowed to stand until completely dry (about 30 seconds). The articles were then lightly sprayed with solution B. 
2,2'-Dipyridil formulation: 2,2'-bipyridine (4g, Acros) and ascorbic acid (1g, Acros) were dissolved in ethanol (100mL, Sigma) followed by the addition of hydrochloric acid $(3 \mathrm{~mL}$, Sigma).

Treatment of articles: The articles were lightly sprayed with the prepared solution using the Ecospray ${ }^{\circledR}$.

Fluorescence Observations

Fluorescence observations were performed using a Mason Vactron Quaser 40 and a Foster and Freeman Crime-Lite ${ }^{\circledR}$ 2. Table 2 presents the appropriate excitation wavelengths and viewing filters for the appropriate enhancement technique.

Table 2 - Excitation wavelength and viewing filters for enhancement techniques

\begin{tabular}{|c|c|c|c|c|}
\hline Chemical Name & $\begin{array}{c}\text { Excitation } \\
\text { Wavelength/nm }\end{array}$ & $\begin{array}{c}\text { Excitation } \\
\text { Filters }\end{array}$ & $\begin{array}{c}\text { Viewing } \\
\text { Filter/nm }\end{array}$ & $\begin{array}{c}\text { Viewing } \\
\text { Filters }\end{array}$ \\
\hline Acid Yellow 7 & $385-509$ & Blue & 510 & Yellow/Orange \\
\hline Acid Violet 19 & $473-548$ & Green & 549 & Orange \\
\hline Solvent Green 7 & $385-469$ & Violet/Blue & 476 & Yellow \\
\hline Acid Red 52 & $503-591$ & Green/Yello & 593 & Red \\
\hline Leuco Crystal Violet & $503-591$ & Green/Yello & 593 & Red \\
\hline Leuco Rhodamine 6G & $468-526$ & Blue/Green & 529 & Orange \\
\hline Fluorescein & $385-509$ & Blue & 510 & Yellow/Orange \\
\hline Hemascein ${ }^{\circledR}$ & $385-509$ & Blue & 510 & Yellow/Orange \\
\hline DFO & $473-548$ & Green & 549 & Orange \\
\hline 1,2-IND & $473-548$ & Green & 549 & Orange \\
\hline DMAC & $473-548$ & Green & 549 & Orange \\
\hline
\end{tabular}

These wavelengths represent the $1 \%$ cut-on and cut-off points and other light sources may use wavelengths representing different cut-on and cut-off points [48]. 


\section{Results and Discussion}

\section{Blood Enhancement Techniques}

\section{Protein Stains}

The non-fluorescent protein stains AB1 and AV17 did not provide any suitable contrast with the dark fabric backgrounds. Nonetheless, the application of oblique lighting on enhanced impressions on black polyester (but not on other black fabrics) provided a notable improvement as illustrated in figure 1. Prior to enhancement with protein stains, oblique lighting failed to provide a suitable visualisation contrast as the blood appeared to absorb the lighting. Phloxine B (acid red 92) is marketed for enhancement of impressions in blood on dark substrates since the reddish-orange development provides suitable contrast with the dark background, however the formulation of phloxine B used in this study did not provide any significant enhancement on any fabric tested. Fluorescent protein stains provided excellent contrast of the impression in blood on dark fabrics. Acid yellow 7 (AY7) provided better enhancement than AV19, AR52 and SG7 in terms of fluorescent intensity and sharpness. The fluorescence for impressions on denim and leather was however weak as pictured in figure 2 . It is hypothesised that the weak AY7 fluorescence of blood impressions on denim and leather may be due to interference from the dye and tanning procedures respectively, used in the manufacturing processes. Fluorescence enhancement on patterned cotton also produced background fluorescence that hindered the visualisation process. This is postulated to be due to the particular dye and finishing of the fabric as no such fluorescence was observed on black cotton. AY7 is not generally recommended for porous items due to background staining, however excellent fluorescent enhancement was observed on black cotton, polyester and nylon with no visible background staining. 


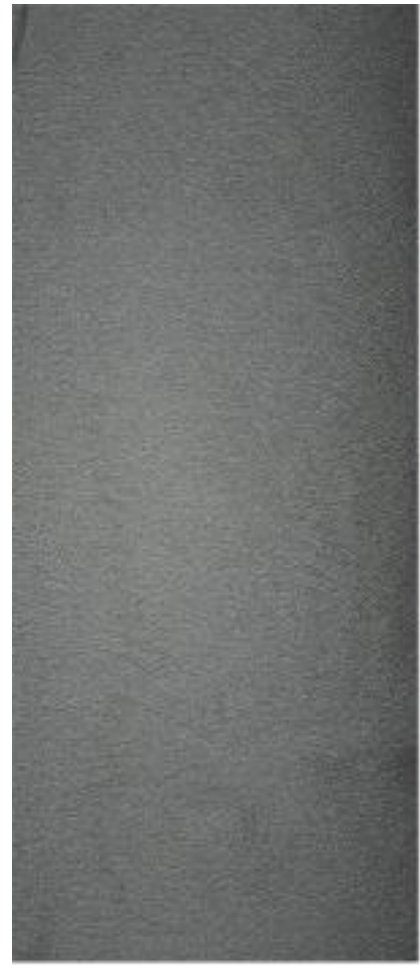

(a)

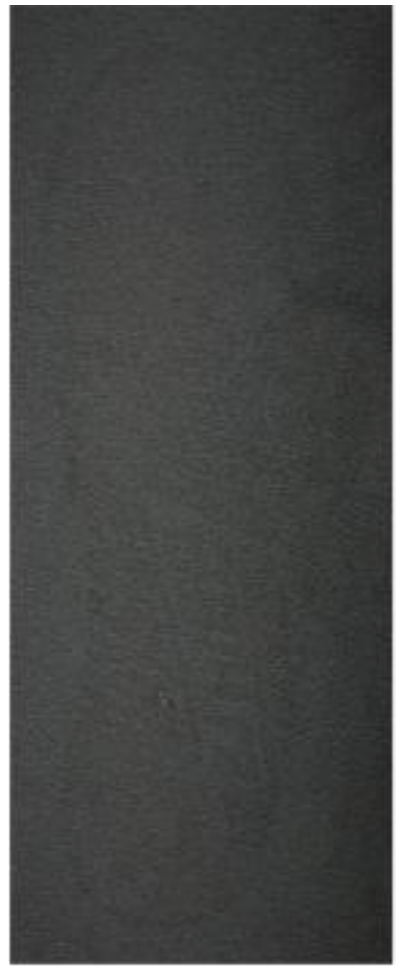

(b)

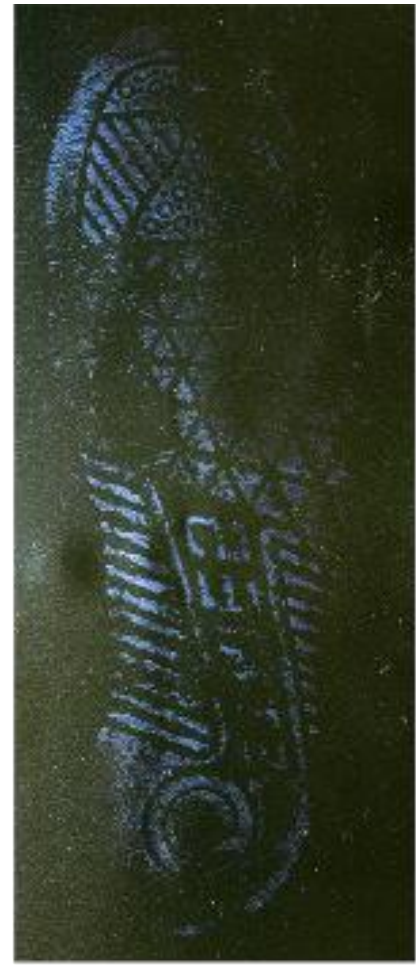

(c)

Figure 1 - Enhancement of a footwear impression in blood on black polyester with AB1: (a) blood impression before enhancement under white light; (b) AB1 enhancement under white light; (c) visualisation of (b) using oblique lighting

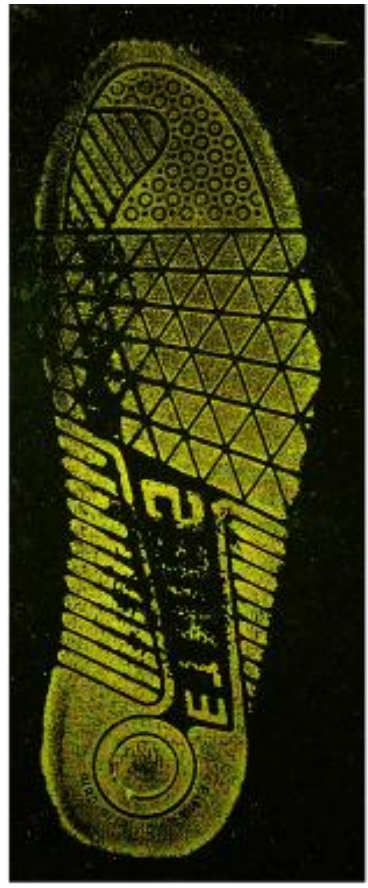

(a)

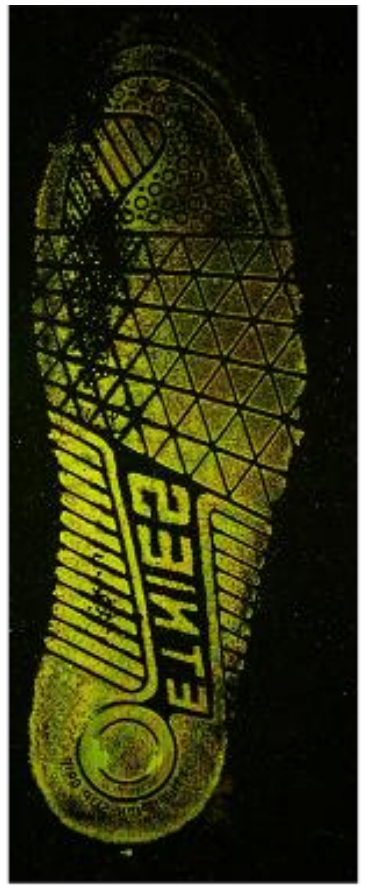

(b)

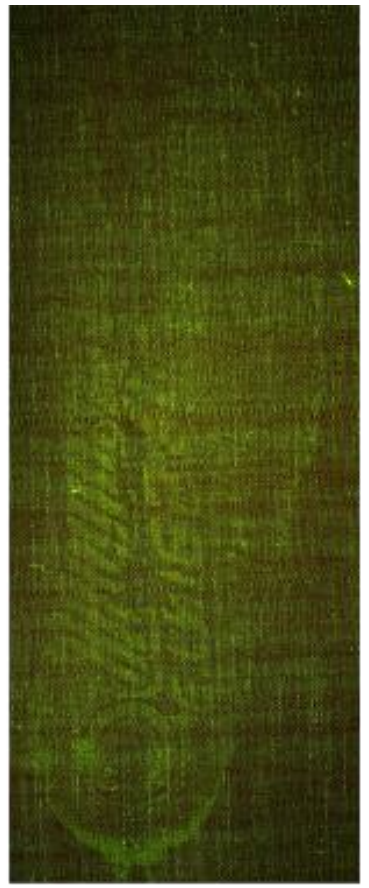

(c)

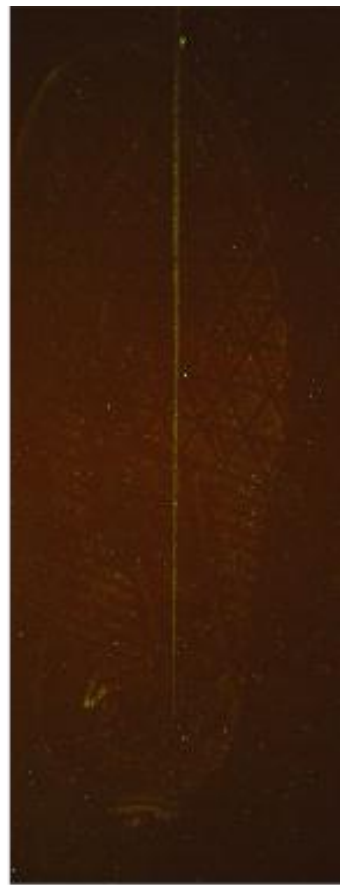

(d)

Figure 2 - Enhancement of a footwear impression in blood with AY7 fluorescence using a Mason Vactron Quaser 40 on: (a) black cotton; (b) black nylon/lycra; (c) denim and (d) bovine leather 
Furthermore, similar fluorescent results were obtained when using a portable Foster and Freeman Crime-Lite ${ }^{\circledR} 2$ with a blue excitation source or a Mason Vactron Quaser 40 with a blue excitation filter $(385-509 \mathrm{~nm})$ and viewed with a yellow/orange filter $(510 \mathrm{~nm})$. A blue laser (460nm) may also create stronger fluorescent results (45).

Research carried out by the Dutch National Forensic Institute (NFI) suggested that AV19 could also be used as a fluorescent protein stain $(18,21)$. Their research indicated that impressions in blood recovered with a white gelatin lifter will fluoresce when treated with AV19. A 1:100 dilution of the AV19 solution was also noted to provide direct fluorescence on the substrate without lifting (18). Some enhancement using this dilution was achieved on the black fabrics (figure 3) but not on denim or leather. No lifting was achieved using AV19 or any other protein stain after lifting with a white gelatin lifter.

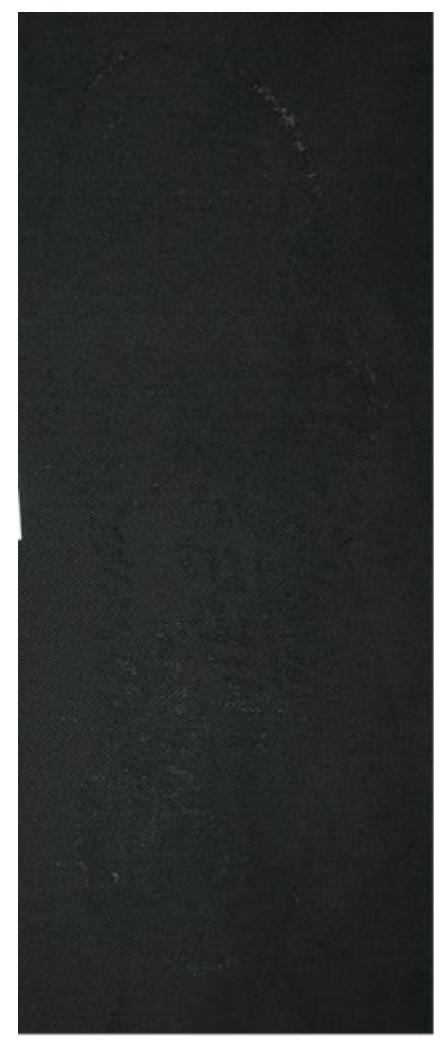

(a)

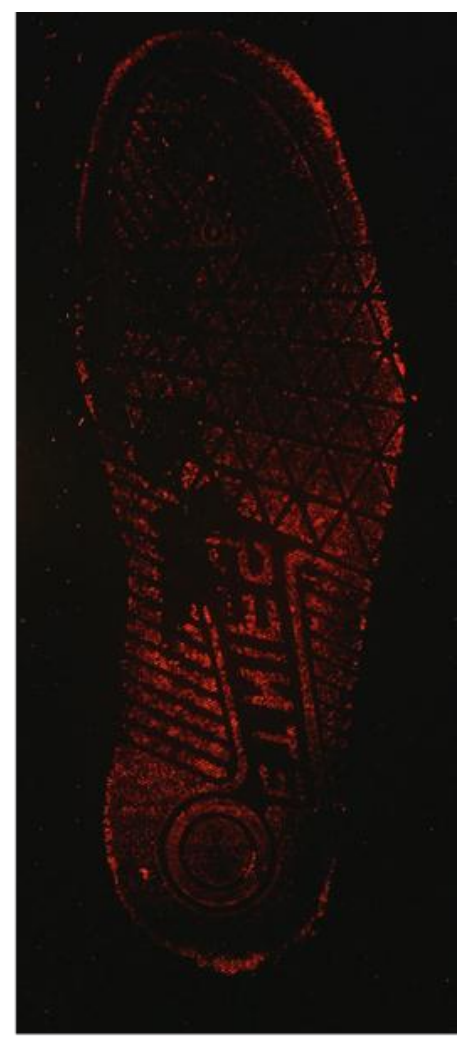

(b)

Figure 3 - Enhancement of a footwear impression in blood on black cotton with AV19: (a) white light; (b) green light $(473-548 \mathrm{~nm})$ 
Heme Reagents

It was noted that prompt photography was necessary due to excessive background staining using these chemical enhancement methods. The purple LCV enhancement failed to provide suitable contrast with the dark fabric background. The use of alternate light sources may counteract these contrast issues because of fluorescence $(26,46)$, however, in this study different excitation filters only provided very weak fluorescence. By comparison a yellow laser improved the fluorescence on dark fabrics (figure 4). The enhancement of footwear impressions in blood on patterned cotton with LCV was successful without the need of alternate light sources as illustrated in figure 5.

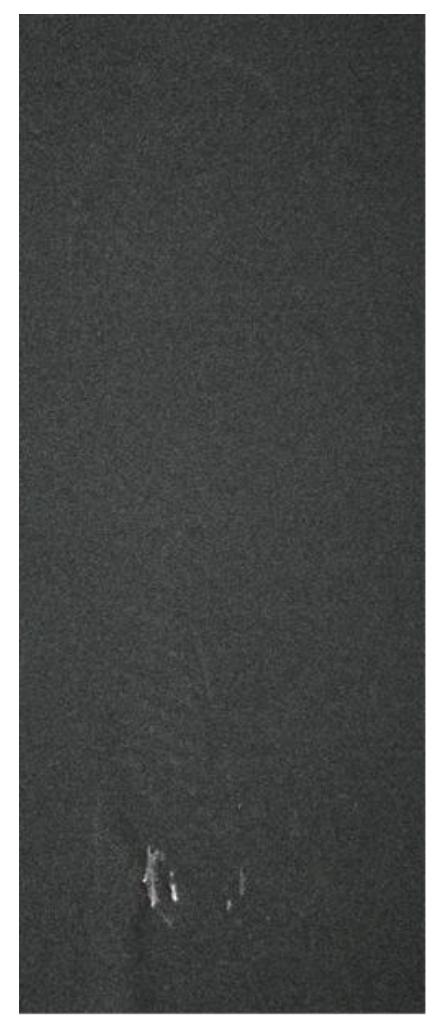

(a)

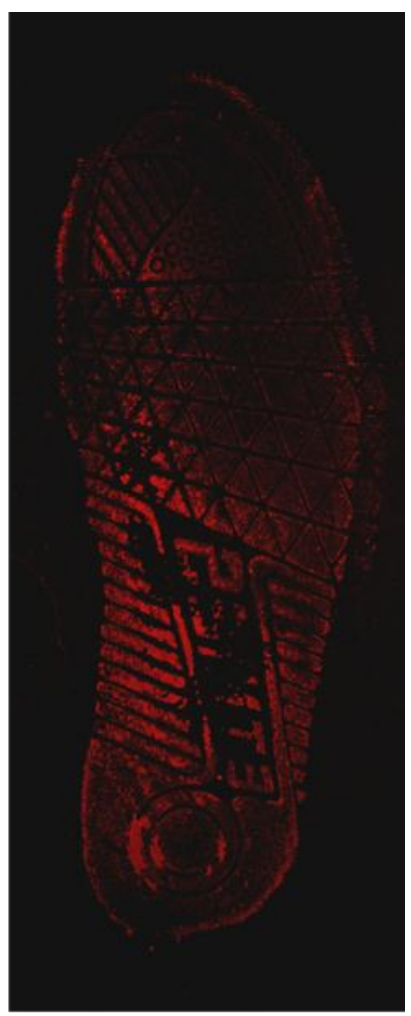

(b)

Figure 4 - Enhancement of a footwear impression in blood on black nylon/lycra and enhanced with LCV: (a) before enhancement and (b) after enhancement using yellow laser $(577 \mathrm{~nm})$ 


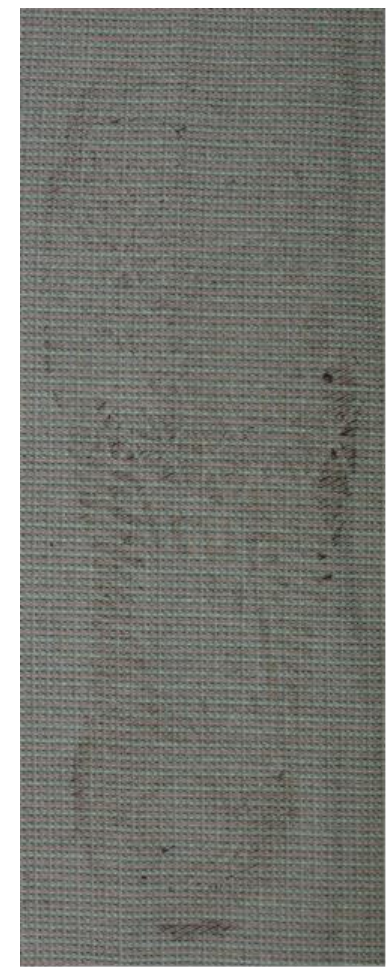

(a)

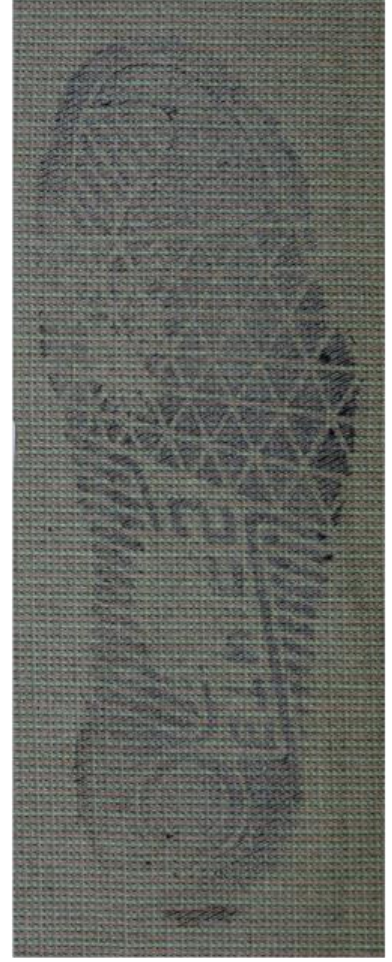

(b)

Figure 5 - LCV enhancement of a footwear impression in blood on patterned fabric: (a) before; (b) after

Fluorescein enhancement of impressions in blood normally requires the use of an appropriate light source for visualisation. In this study, for black fabrics and leather, the need of an alternate light source was eliminated as a colourimetric reaction was instantaneously visible after the application of chemicals (figure 6). However, an alternate light source was necessary for the visualisation of the footwear impression in blood on denim. Prompt photography was also required as the visualised bright yellow colour started to fade after a few minutes. No background staining on denim was observed, either initially or over time, as suggested in other research (47). 

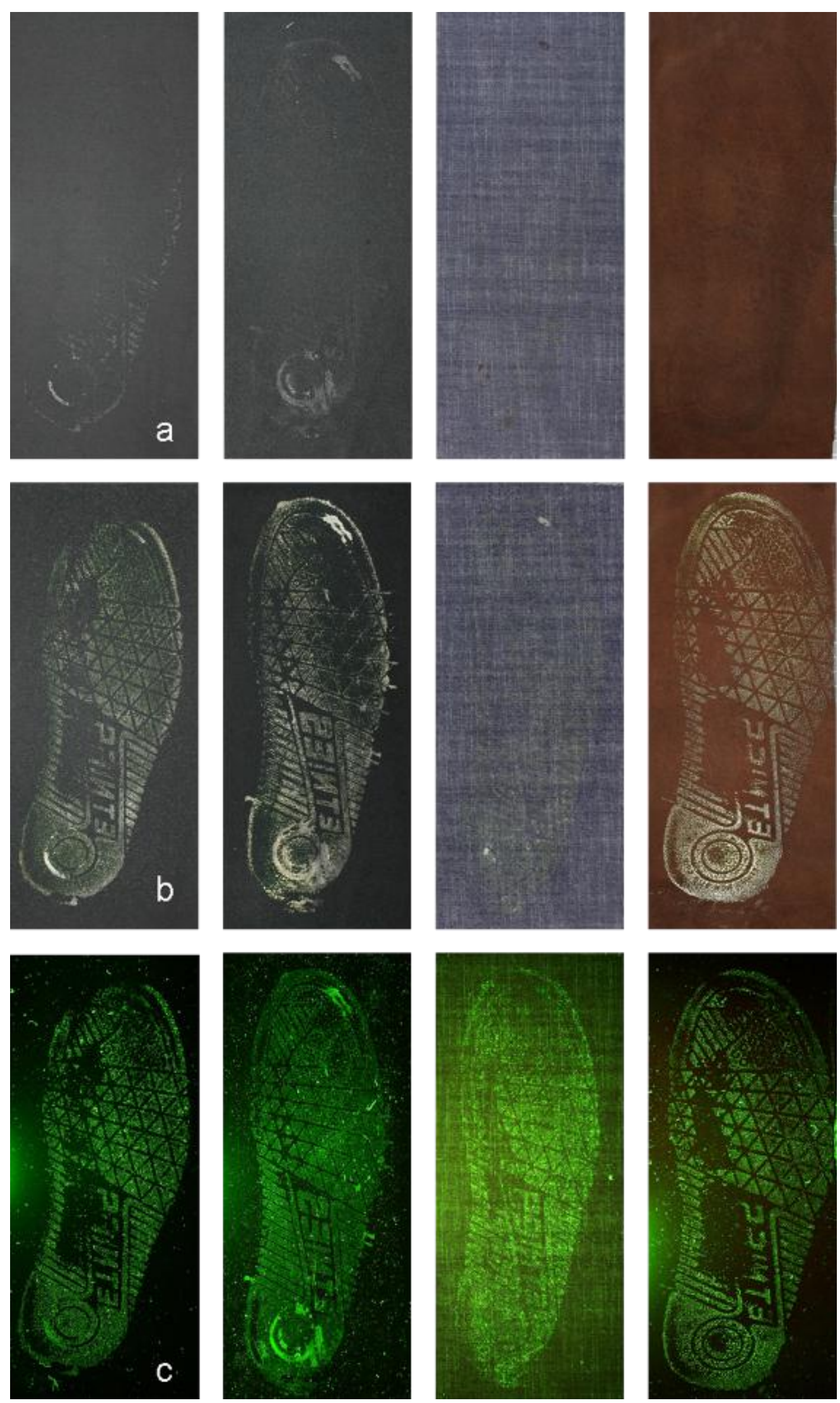

Figure 6 - Enhancement of a footwear impression in blood on (from left to right) black cotton, black nylon/lycra, blue denim and bovine leather using fluorescein: (a) 7 days old footwear impressions in blood; (b) after fluorescein enhancement under white light; (c) after fluorescein enhancement using a Quaser 40 blue excitation source (385-509nm) 
Hemascein ${ }^{\circledR}$ is a commercially available product using the fluorescein enhancement technique. It avoids the reduction reaction over zinc and makes the product ideal for crime scene use. The product comes supplied with two ABAsprays ${ }^{\circledR}$ for mist spraying of fluorescein and hydrogen peroxide. On application of the product with these sprayers, it was immediately noticed that the mist was less fine than the Ecosprayer supplied by Bluestar ${ }^{\circledR}$. Diffusion was not only present on synthetic fabrics but also on natural fabrics such as cotton, however, the extent of diffusion on natural fabrics was less pronounced. The fluorescence examination was carried within 10 minutes of chemical application, however, the fluorescence observed was either minimal or non-existent. The re-application of reagents provided some additional enhancement but increased the diffusion already present as illustrated in figure 7. Figure $7 \mathrm{~b}$ also depicts the successful enhancement of impressions in blood on patterned cotton with Hemascein ${ }^{\circledR}$.

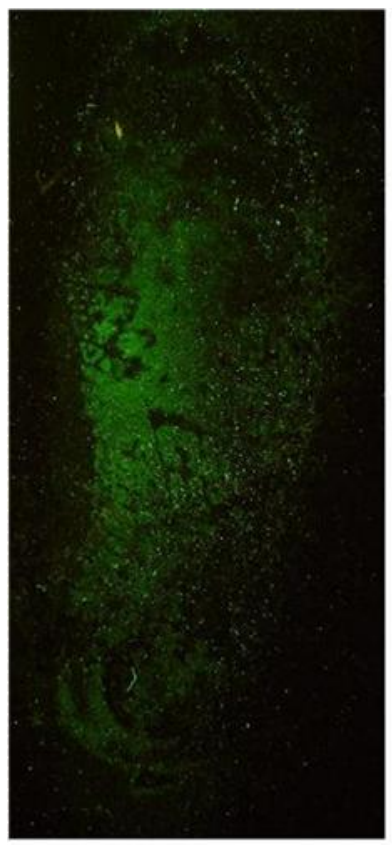

(a)

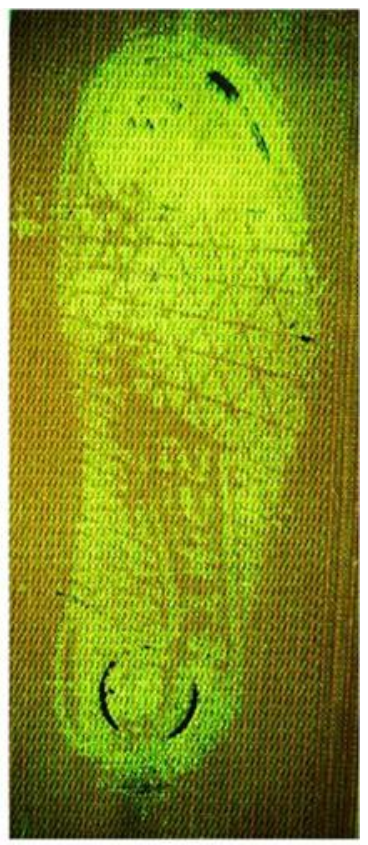

(b)

Figure 7 - Enhancement of a footwear impression in blood using Hemascein ${ }^{\circledR}$ : (a) black nylon/lycra; (b) patterned cotton 
This was the only fabric where Hemascein ${ }^{\circledR}$ produced a superior result to fluorescein prepared from raw chemicals. Furthermore, Hemascein ${ }^{\circledR}$ fluorescence was weak or nonexistent and re-application of the chemicals did not provide useful additional enhancement.
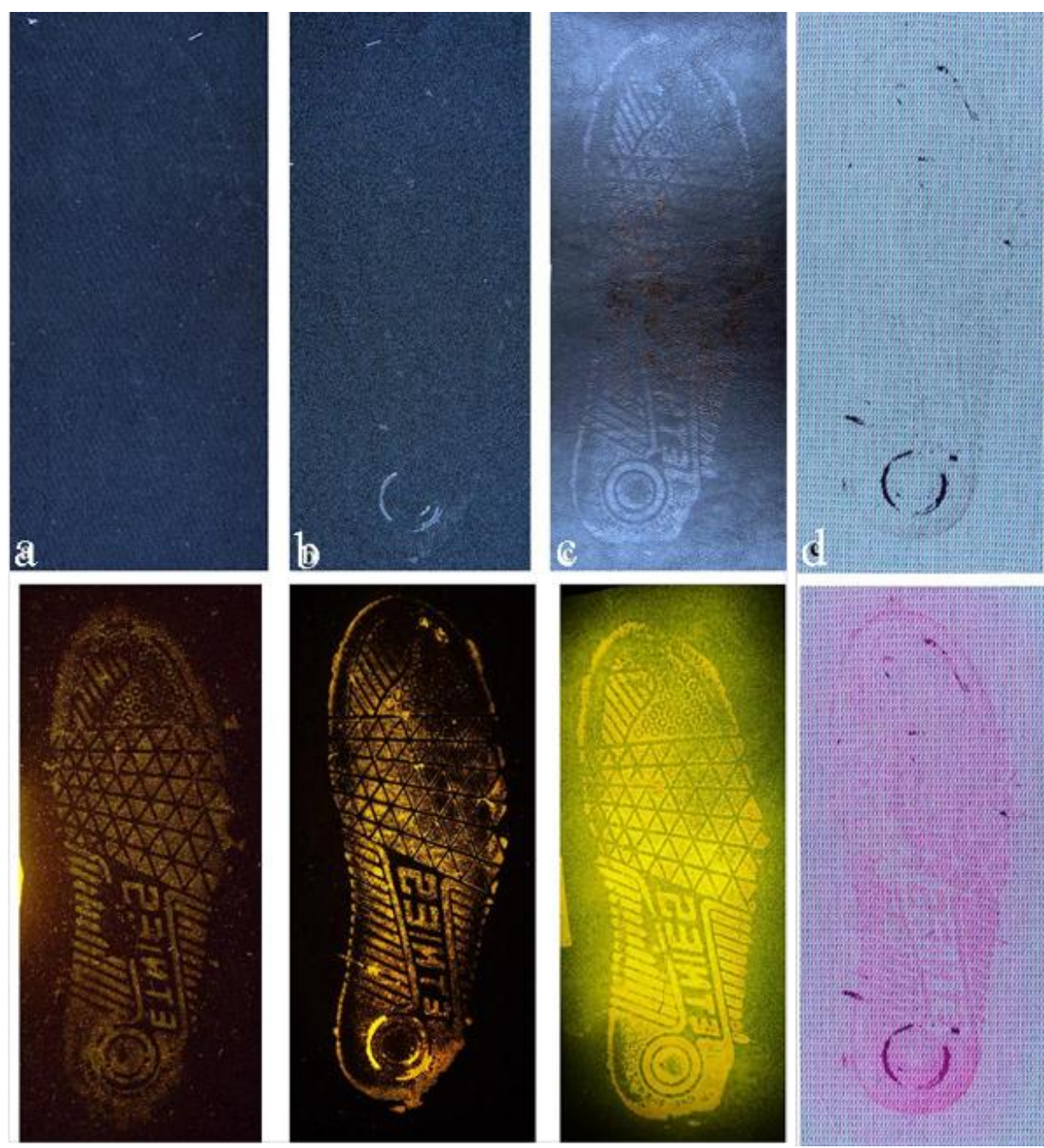

Figure 8 - Enhancement of a footwear impression in blood using LR6G fluorescence, before (top) and after enhancement (bottom): (a) black cotton; (b) black nylon/lycra; (c) leather; (d) patterned cotton (visual enhancement)

Leuco rhodamine 6G (LR6G) was prepared by reduction over zinc of the commercially available rhodamine $6 \mathrm{G}$ as described by Yapping (31). LR6G is oxidised to rhodamine $6 \mathrm{G}$ (R6G) through a reaction with the heme in haemoglobin to produce a red colour. Yapping (31) however, failed to mention the safety issues associated with the use of zinc metal as a reducing agent and that rhodamine $6 \mathrm{G}$ fluoresces when excited with the appropriate 
wavelength of light. As with LCV, rapid photography of the enhanced mark was required. Visual enhancement on dark coloured fabrics with LRG6 was limited or non-existent, however the use of a Mason Vactron 40 provided suitable fluorescence enhancement using a blue/green excitation filter (band pass filter 468-526nm at $1 \%$ cut-on and cut-off points respectively) and viewed with a long pass $529 \mathrm{~nm}$ filter (1\% cut-on point) as pictured in figure 8. Visualisation of the impressions in blood on patterned cotton was superior to subsequent fluorescence due to extensive background fluorescence from the fabric (figure 8d).

Forensic Bluestar ${ }^{\circledR}$ Magnum produced a strong chemiluminescence in the enhancement of impressions in blood on all fabrics utilised in the study as depicted in figure 9. This commercial product is advertised as providing stronger and longer chemiluminescence than other luminol formulation. No background staining occurred on leather samples although some diffusion and blurring occurred during the enhancement of impressions in blood on synthetic fabrics which was limited by spraying the reagents as a fine mist.

Previous work by the Home Office Centre for Applied Science and Technology, CAST (formerly the Home Office Scientific Development Branch, HOSDB) $(22,48)$ had concluded that peroxidase reagents were not suitable for the enhancement of fingerprints in blood as the minute details are not preserved, but could work very well with the enhancement of footwear impressions in blood. Additional advantages of luminol over fluorescein include the ease of preparation, a one-step spraying process and the fact that no alternative light sources are required. This was the only technique that provided suitable enhancement on all fabrics in this study, however, the chemiluminescence is short lived although total darkness was not required for visualisation. 

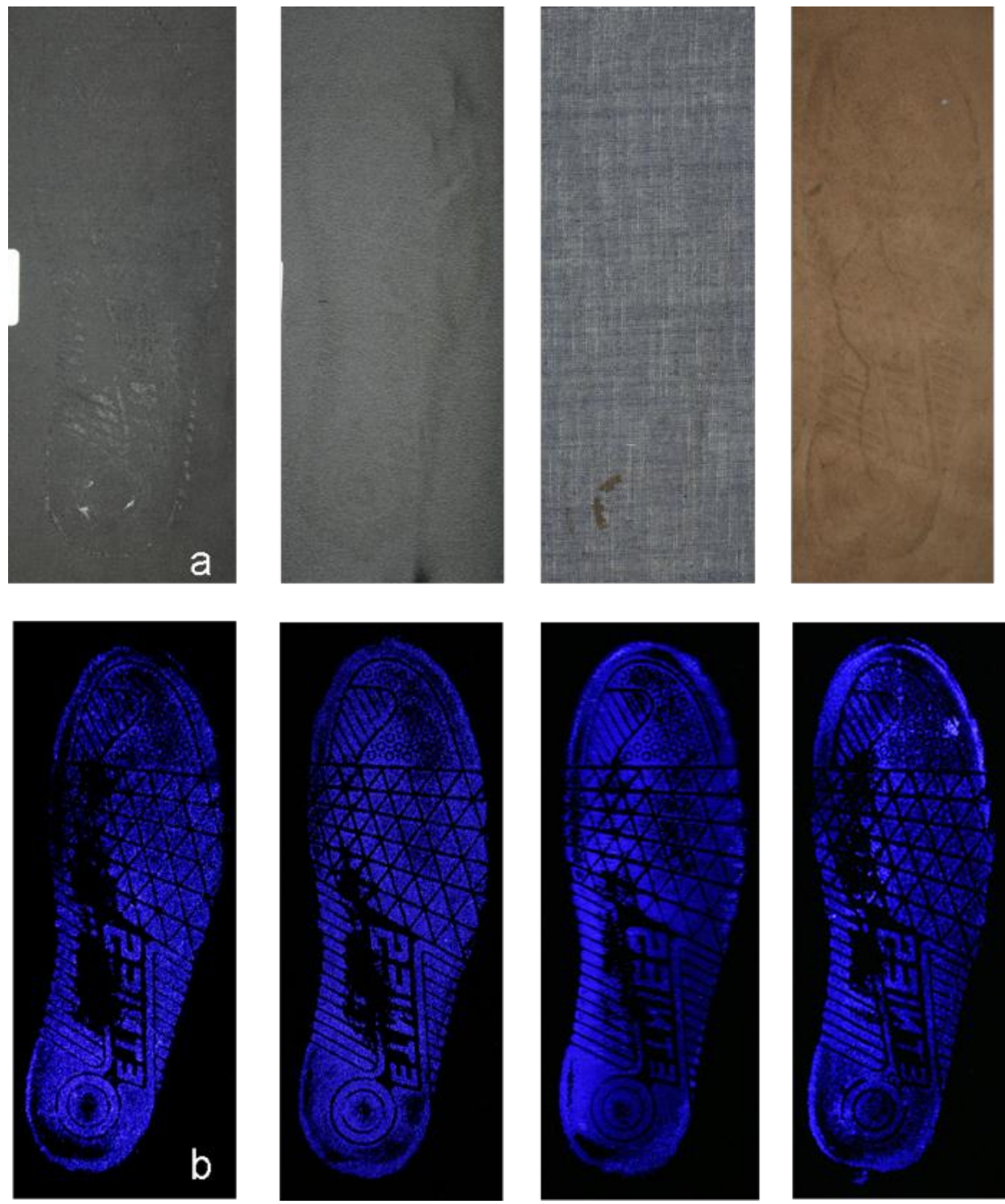

Figure 9 - Enhancement of a footwear impression in blood on (from left to right) black cotton, black polyester, blue denim and bovine leather using fluorescein: (a) 7 days old footwear impressions in blood; (b) luminol enhancement of footwear impressions 
Amino Acid Staining

Results obtained with DFO and 1,2-indanedione were poor despite the potential advantage of fluorescence. Some enhancement was achieved using ninhydrin for impressions in blood on patterned cotton as illustrated in figure 10.

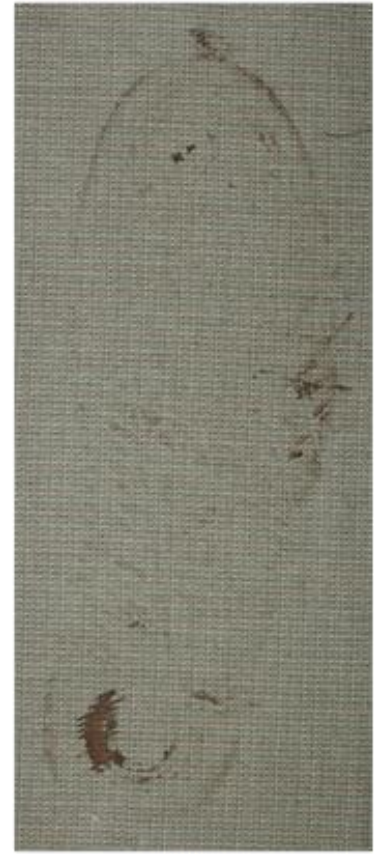

(a)

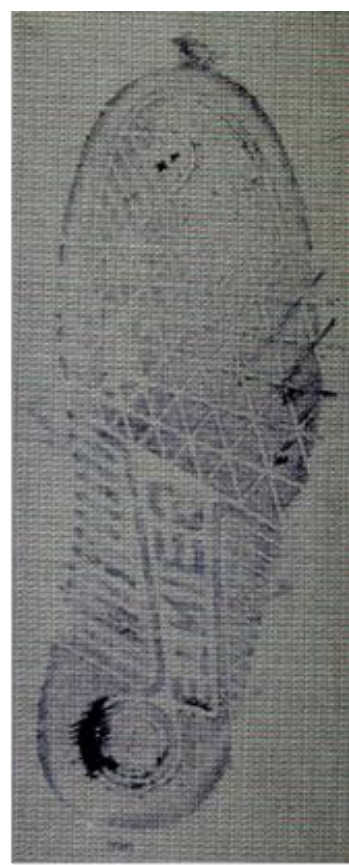

(b)

Figure 10 - Enhancement of a footwear impression in blood on patterned cotton using ninhydrin: (a) before; (b) after

Other techniques

Alginates provided very good results for the enhancement of footwear impressions in blood. Lifting with alginate followed by enhancement of the alginate lift using acid black 1 provided good results for impressions in blood on all fabrics in the study as illustrated in figure 11 . 


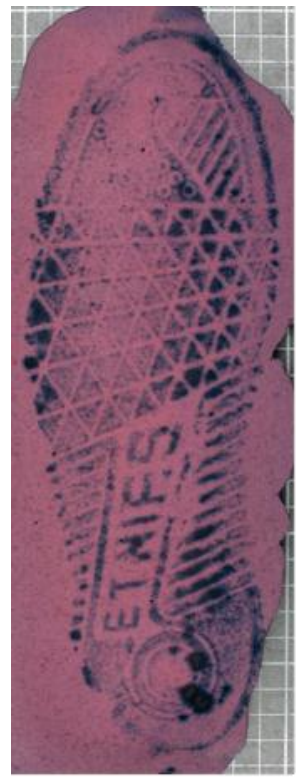

(a)

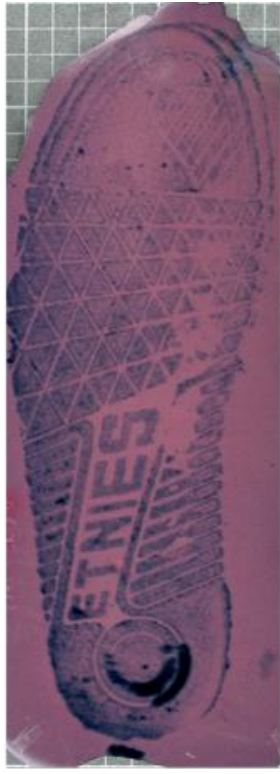

(b)

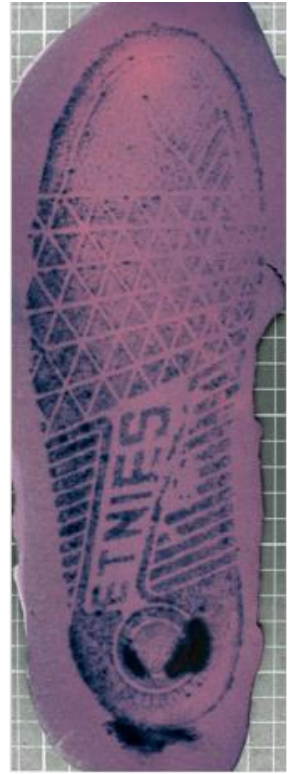

(c)

Figure 11 - Lifting and enhancement of a footwear impression in blood using GC Aroma Dust Fine III alginate followed by acid black 1 treatment: (a) black cotton; (b) black nylon/lycra; (c) denim

Treatment of the impression in blood with acid black 1 followed by alginate lifting also provided good results but the impression appeared to be of inferior sharpness and quality. There are various alginates commercially available, however, GC Aroma Dust Fine III provided the best overall results in terms of lifting capability, robustness of the cast and homogeneity which is in line with previous research (36). The alginate cast produced a mirror image of the impression and was subject to shrinkage over time. The efficacy of the technique was limited by the fact that no sequential enhancement was obtained on the remaining impression in blood on the fabric after lifting with the alginate.

The formulation of white powder suspension suggested by Bergeron (34) was investigated. Slight enhancement was observed on black cotton, however, in most instances the enhancement was poor or non-existent as was observed for impressions on denim and leather. The best enhancement was observed on black polyester and no enhancement was achieved on black nylon/lycra due to background staining as illustrated in figure 12. The application was also hindered by nozzle blockages of the sprayer. 

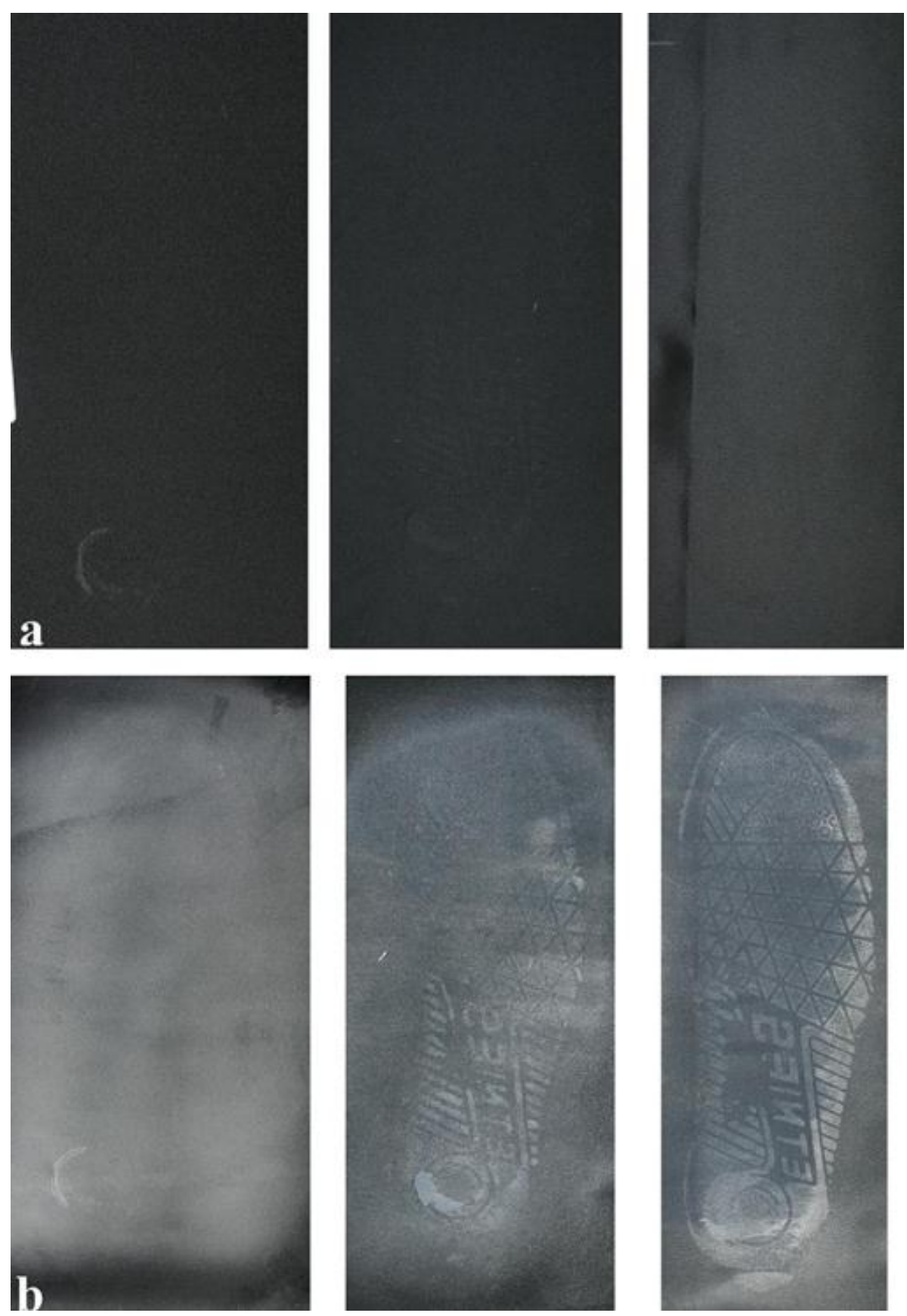

Figure 12 - The enhancement of footwear impressions in blood with white powder suspensionon black nylon/lycra, cotton and polyester: (a) before enhancement; (b) after enhancement

Summary of blood enhancement reagents

A summary of the enhancement abilities and observations for all reagents specific to the chemical enhancement of blood on fabric is presented in table 3. 
Table 3 - Summary of Blood Enhancement Techniques on Dark and Patterned Fabrics

\begin{tabular}{|c|c|c|}
\hline Techniques & Advantages & Disadvantages \\
\hline Protein Stains & $\begin{array}{c}\text { Cheap } \\
\text { Easy to apply } \\
\text { Potential fluorescence }\end{array}$ & $\begin{array}{c}\text { Multiple process } \\
\text { Background staining }\end{array}$ \\
\hline Haem Reagents & $\begin{array}{l}\text { Relatively cheap } \\
\text { One-step process } \\
\text { Fast application }\end{array}$ & $\begin{array}{c}\text { Background staining } \\
\text { Health effects } \\
\text { Diffusion }\end{array}$ \\
\hline Amino Acid Staining & $\begin{array}{c}\text { Easy to apply } \\
\text { Suitable on patterned background }\end{array}$ & $\begin{array}{l}\text { Very expensive solvents } \\
\text { Not suitable on black fabrics } \\
\text { Requires wet/dry oven }\end{array}$ \\
\hline Alginates & $\begin{array}{l}\text { Good results on all fabrics } \\
\text { Post processing of alginate }\end{array}$ & $\begin{array}{c}\text { Expensive } \\
\text { Cumbersome } \\
\text { Not suitable for sequential } \\
\text { enhancement }\end{array}$ \\
\hline
\end{tabular}

Although a recently new, novel fluorogenic method for lifting, enhancing and preserving impressions in blood produced excellent enhancement results on various substrates, including fabric, the cost of such lifts is prohibitive for many laboratories [49]. The use of acid yellow 7 is a cheap, readily available and an easy technique to apply on dark fabrics where immersion or spraying methods may be used. LCV and other heme reagents are also cost effective and may be easily employed in the laboratory or in the field, however, there are some health and safety concerns. Hemascein ${ }^{\circledR}$ was clearly less effective than the fluorescein reagent prepared from raw chemicals and the sprayers supplied with Hemascein ${ }^{\circledR}$ did not provide a fine mist required for the successful enhancement of impressions on fabric in comparison to the Ecosprayers $^{\circledR}$. The use of amino acid staining techniques yielded limited results on dark fabrics and required the use of expensive solvents such as HFE-7100 and HFE-71DE and suitable ovens (wet and dry).

Luminol was the only technique to enhance impressions in blood on all fabrics however, acid yellow 7 produced superior enhancement on black cotton, polyester and nylon/lycra. LCV and ninhydrin provided immediate results on patterned cotton where acid yellow 7 failed. Impressions in blood on denim and leather were best enhanced using luminol and fluorescein. 
None of the four techniques investigated provided suitable enhancement (visual or fluorescent) on black fabrics, leather or denim possibly because of the interaction of the dyes with the enhancement chemicals leading to fluorescence quenching. Enhancement of urine impressions using ninhydrin on patterned cotton was weak but observable despite the lack of fluorescence capability by the technique (figure 13). Fluorescent and occasional visual enhancement was obtained on patterned fabric with DFO, 1,2-indanedione and DMAC as illustrated in figure 14. Some fluorescence was also observable prior to chemical enhancement.

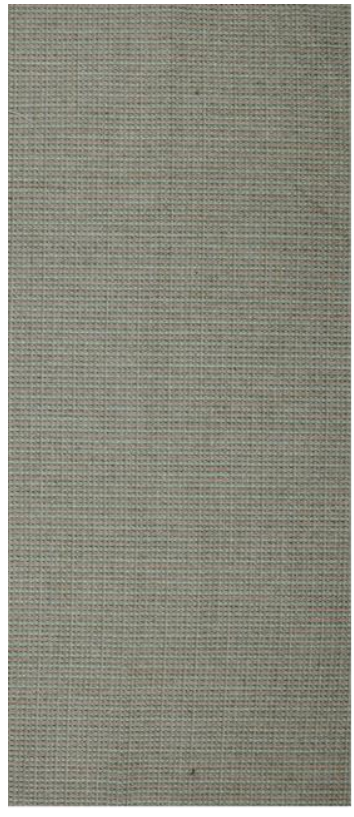

(a)

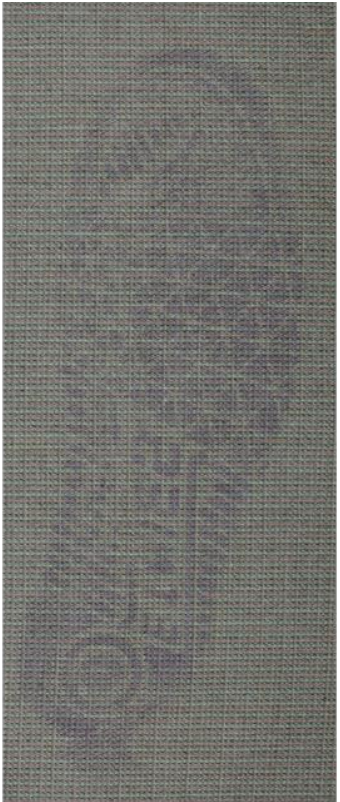

(b)

Figure 13 -Ninhydrin enhancement of a footwear impression in urine on patterned cotton: (a) before; (b) after 

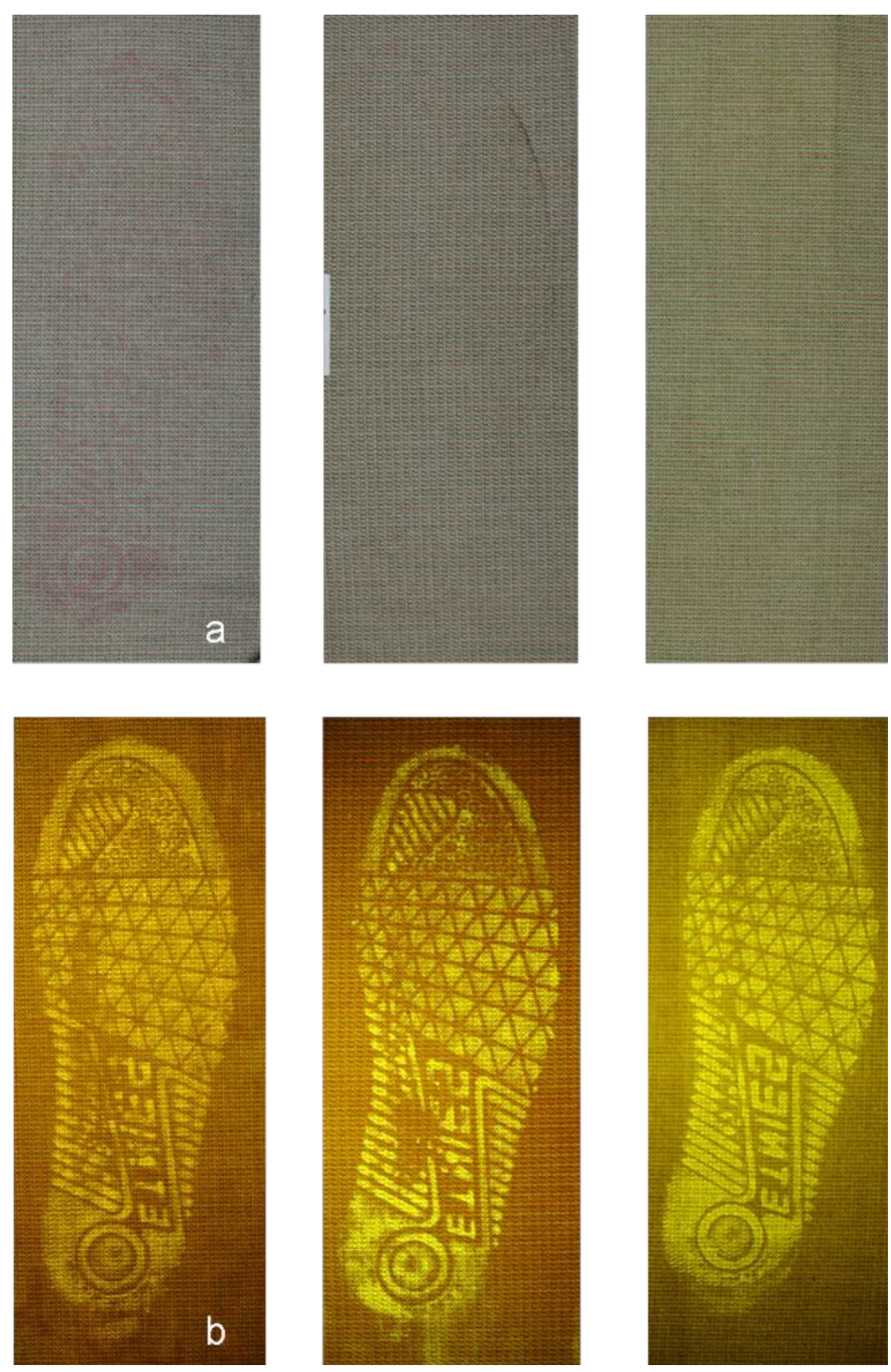

Figure 14 - Enhancement of footwear impressions in urine on patterned cotton with (from left to right) with DFO, 1,2-indanedione and DMAC: (a) visual enhancement; (b) associated fluorescent enhancement

Summary of urine enhancement reagents

The reagents investigated did not provide any enhancement of impressions made in urine on dark fabrics, however some excellent results were obtained on patterned cotton. Table 4 summarises the results obtained. 
Table 4 - Summary of Urine Enhancement Techniques on Dark and Patterned Fabrics

\begin{tabular}{|c|l|c|}
\hline Amino Acid Staining & Advantages & Disadvantages \\
\hline Ninhydrin & Easy to apply & $\begin{array}{c}\text { Background staining } \\
\text { Expensive solvents } \\
\text { Requires wet oven } \\
\text { No fluorescence }\end{array}$ \\
\hline DFO & $\begin{array}{c}\text { Easy to apply } \\
\text { Fluorescence }\end{array}$ & Expensive solvents \\
\hline 1,2 -indanedione & $\begin{array}{c}\text { Easy to apply } \\
\text { Fluorescence }\end{array}$ & Cumbersome Process \\
\hline DMAC & $\begin{array}{c}\text { Easy to apply } \\
\text { Cheap } \\
\text { Fluorescence }\end{array}$ & \\
\hline
\end{tabular}

\section{Soil Enhancement Techniques}

In general, enhancement of soil-based impressions was minimal or non-existent on all black fabrics, leatherette and denim due to poor contrast with the background, but worked well on patterned fabric. Furthermore, none of the techniques utilised demonstrated fluorescence. The enhancement reagents were applied on impressions in mud prepared from different geographical regions in Scotland, U.K. The vibrancy of the colour enhancement observed appeared to be dependent on the type of soil where the soils collected from Wemyss bay and Kilbirnie provided superior enhancement. Impressions on polyester were easily visualised with oblique lighting before chemical treatment as illustrated in figure 15 , similar to protein stain enhancement of impressions in blood. Visualising of the impression with oblique lighting after chemical treatment provided enhancement that was inferior to that before chemical treatment. 


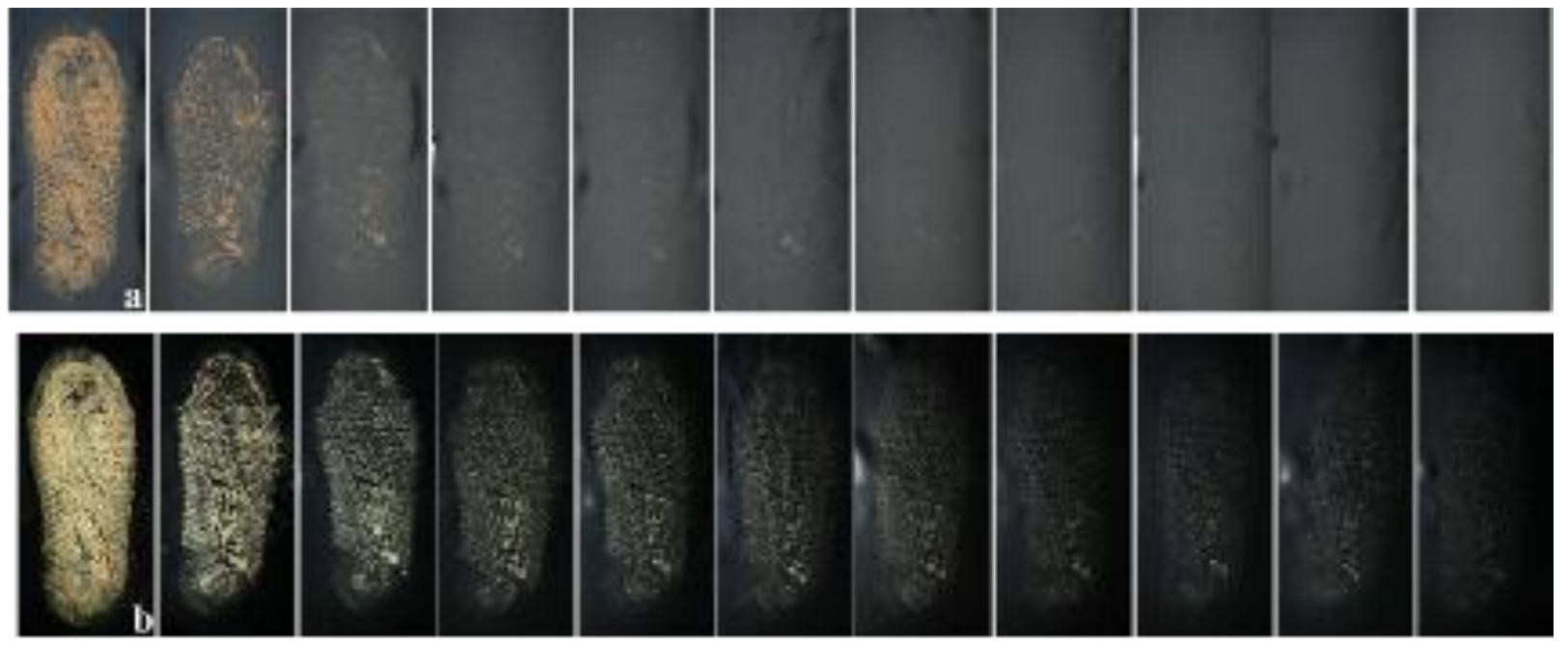

Figure 15 - Chemical enhancement of a diminishing series of footwear impressions in mud, prepared with Wemyss Bay (UK) soil on black polyester, with potassium thiocyanate: (a) 1 week old diminishing series; (b) oblique lighting observation of (a)

Previous research (37) reported ammonium and potassium thiocyanate as both working equally well for the enhancement of muddy footwear impressions and these observations were also made in this study.

The inclusion of water in the formulation of potassium ferrocyanide (figure 16) resulted in a formulation prone to diffusion once applied to the fabrics. This was exacerbated because of the necessity to apply two solutions. On dark fabrics, the contrast between the blue colour and the background was difficult to visualise and the enhancement did not greatly improve on what could already be seen visually.

The enhancement arising from ammonium pyrrolidinedithiocarbamate produced a black colour and as a result, enhancement on dark fabrics was limited or in most cases non-existent due to poor contrast but reasonable enhancement was obtained on patterned cotton as illustrated in figure 17. The technique also requires two solutions increasing the potential for diffusion of the mark to occur. 

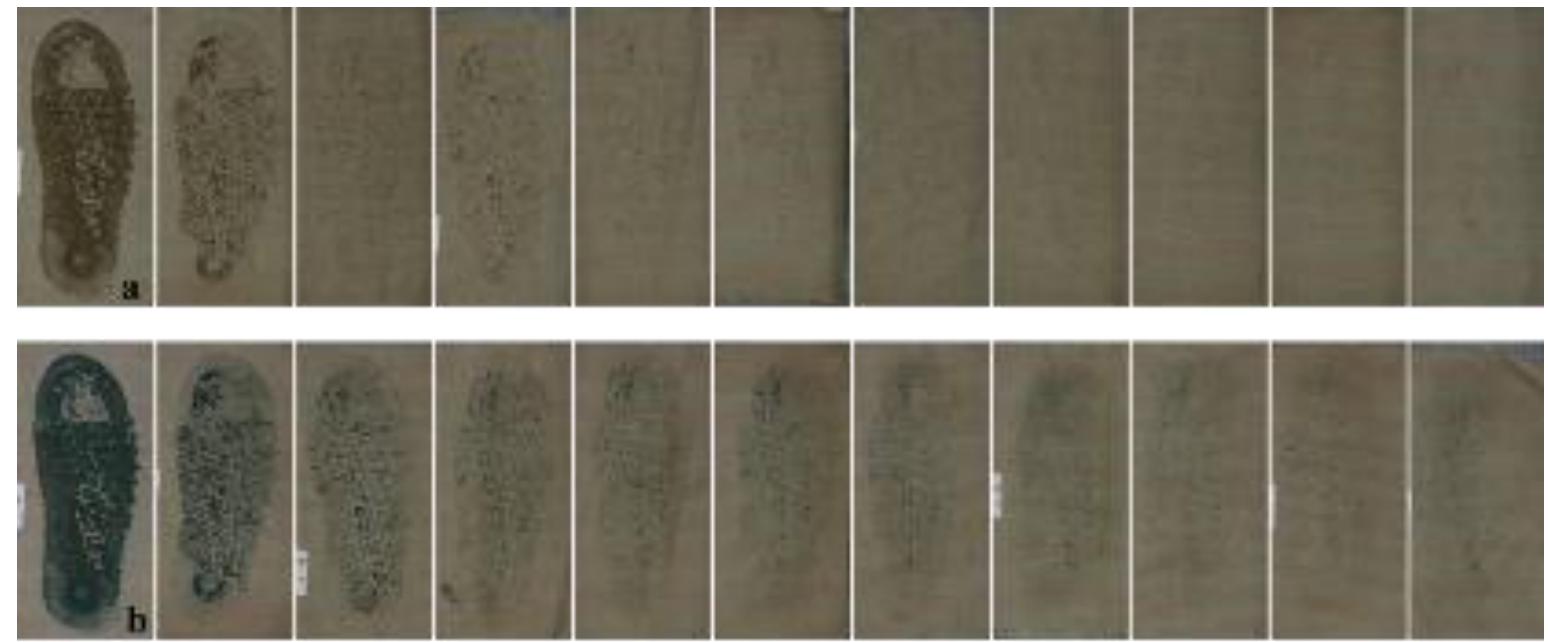

Figure 16 - Chemical enhancement of a diminishing series of footwear impressions in mud, prepared with Kilbirnie (UK) soil on pattered cotton, with potassium ferrocyanide: (a) before; and (b) after enhancement
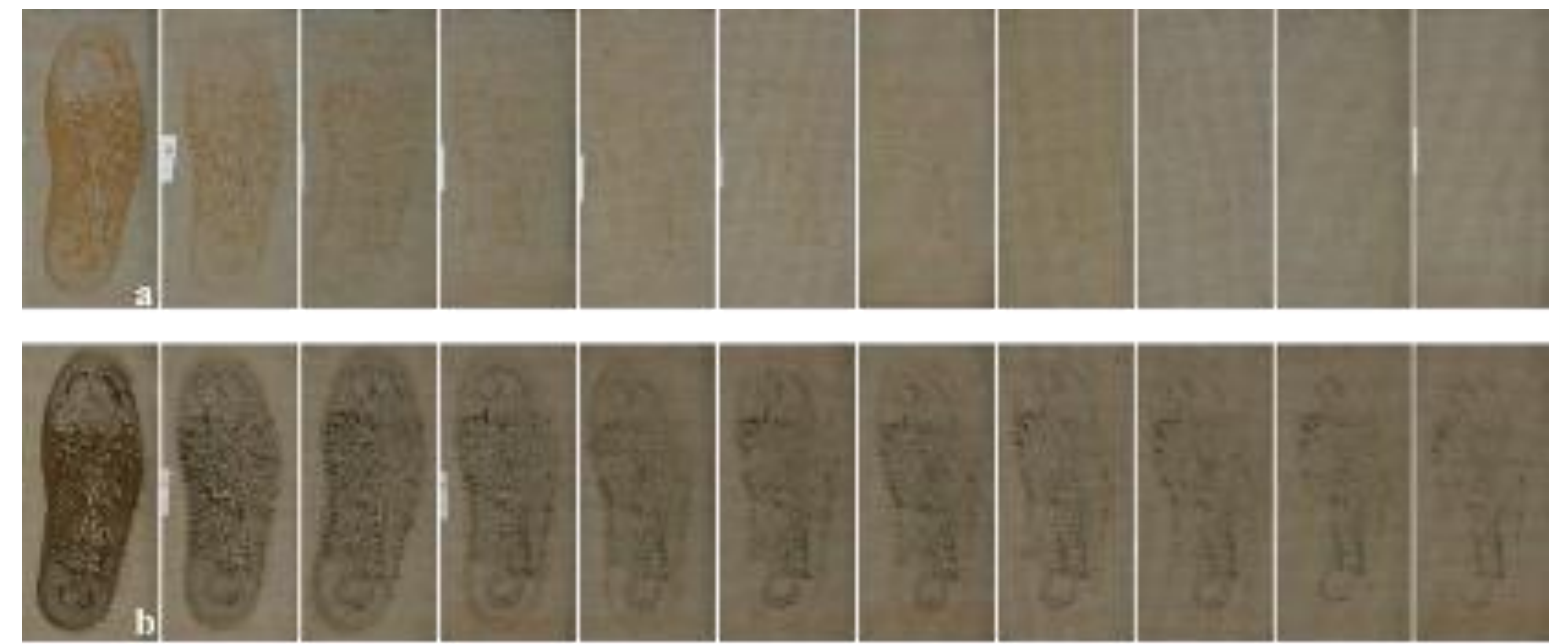

Figure 17 - Chemical enhancement of a diminishing series of footwear impressions in mud, prepared with Wemyss Bay (UK) soil on patterned cotton, with APD: (a) before; and (b) after enhancement

Best results were obtained using 2,2'-dipyridil, where enhancement was observed on dark fabrics up to the third or fourth impression of a diminishing series (figure 18) and good enhancement was obtained on patterned cotton (figure 19). The colour change required 3 to 5 minutes to initially develop, reaching a maximum after about 24 hours. Re-application of the reagent was also possible without any diffusion taking place. This contrasts with results reported by Someha (40) where potassium thiocyanate was found to be the best enhancement technique. 

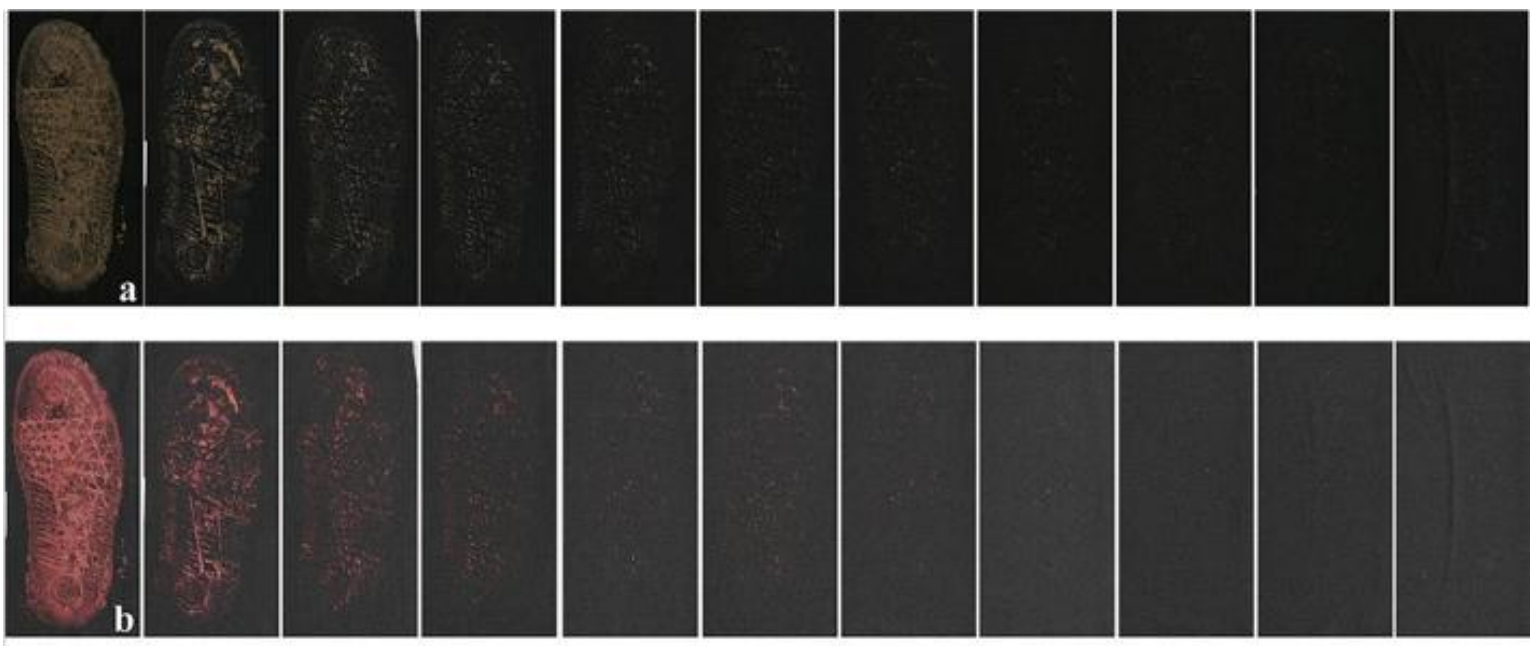

Figure 18 - Chemical enhancement of a diminishing series of footwear impressions in mud, prepared with Kilbirnie (UK) soil on black nylon/lycra, with 2,2'-dipyridil: (a) before; and (b) after enhancement

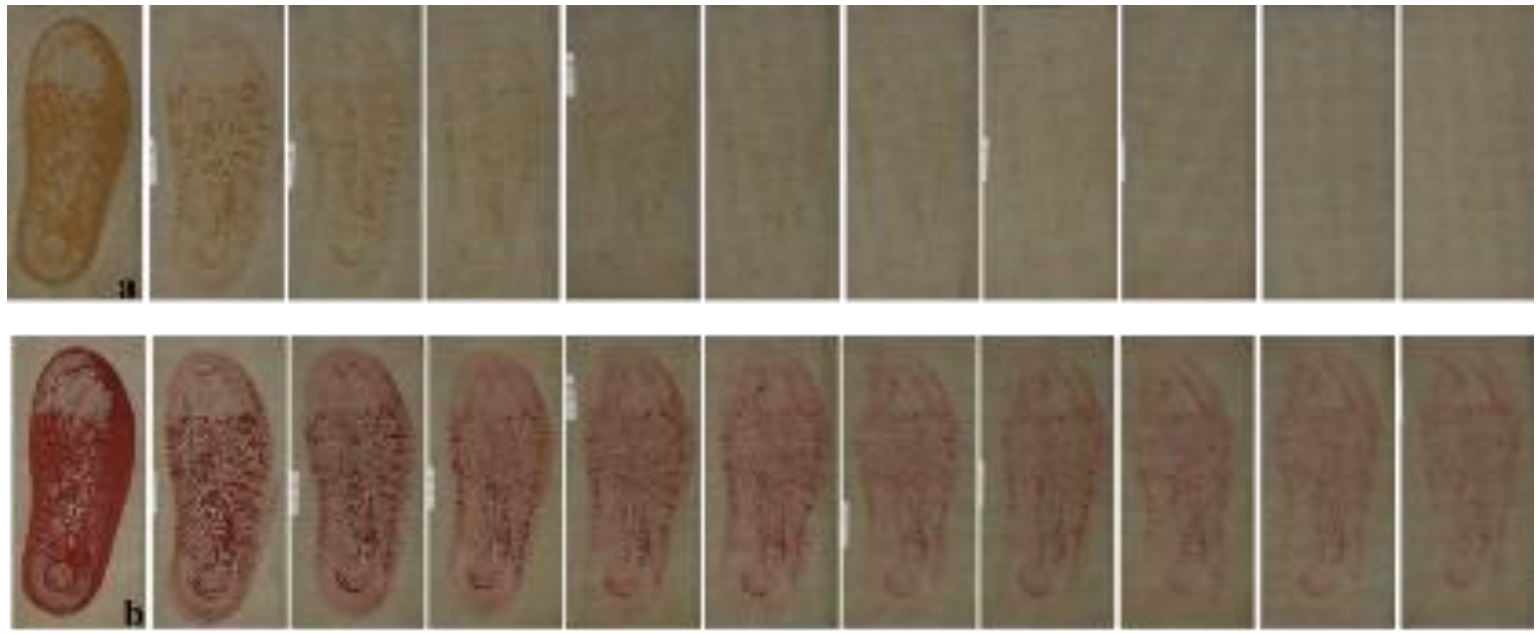

Figure 19 - Chemical enhancement of a diminishing series of footwear impressions in mud, prepared with Wemyss Bay (UK) soil on patterned cotton, with 2,2'-dipyridil: (a) before; and (b) after enhancement

Summary of soil enhancement reagents

Similar to urine impressions, the enhancement reagents provided suitable enhancement on patterned cotton however enhancement on black and dark fabrics, leatherette and denim was limited. Table 5 summarises the results obtained which suggest that 2,2'-dipyridil might be a suitable replacement to the more commonly utilised potassium thiocyanate. 
Table 5 - Summary of Soil Enhancement Techniques on Dark and Patterned Fabrics

\begin{tabular}{|c|c|c|}
\hline Iron Target Compounds & Advantages & Disadvantages \\
\hline Potassium Thiocyanate & Easy to apply & $\begin{array}{c}\text { Slight diffusion } \\
\text { Toxic/noxious fumes } \\
\text { Requires separation }\end{array}$ \\
\hline Cotassium Ferrocyanide & Cheap & Slight diffusion \\
(Blue) & Easy to apply & -step process \\
\hline Ammonium & Cheap & Slight diffusion \\
Pyrrolidinedithiocarbamate & Easy to apply & \\
(Black) & Cheap & Slight diffusion \\
\hline 2,2'-Dipyridil & Easy to apply & \\
(Red) & Cheap & \\
& One-step process & \\
\hline
\end{tabular}

Table 6 provides an overall summary of the results obtained across all fabrics and for each contaminant.

\section{Conclusion}

This study revealed that chemical enhancement on porous surfaces such as fabric is possible.

Due to the nature of the fabrics used, individual characteristics from the footwear sole were not observed before or after enhancement, however the main features and words on the sole were visualised. Successful enhancement results were obtained for the enhancement of impressions in blood on black, dark and patterned fabrics where fluorescence aided to improve the contrast with the background. For other contaminants (urine and soil), enhancement was inferior to impressions in blood and fluorescence was not possible. Future work will address why fluorescence on black fabrics was not successful and the development of fluorescent techniques for the detection of iron. 
Table 6 - Summary of the ability of the techniques to enhance impressions in blood, urine and soil $(* * *=$ excellent; - = none)

\begin{tabular}{|c|c|c|c|c|c|c|c|}
\hline Enhancement Techniques & Contaminant & Black Cotton & Black Polyester & $\begin{array}{c}\text { Black Nylon }(82 \%) / \\
\text { Lycra }(\mathbf{1 8 \%})\end{array}$ & Patterned Cotton & $\begin{array}{c}\text { Leather/ } \\
\text { leatherette }\end{array}$ & Blue denim \\
\hline Acid Yellow 7 & Blood & $* * *$ & $* * *$ & $* * *$ & - & $*$ & $*$ \\
\hline Acid Violet 19 & Blood & $*$ & $*$ & $*$ & - & - & - \\
\hline Solvent Green 7 & Blood & $*$ & $*$ & $*$ & - & - & - \\
\hline Acid Red 52 & Blood & $*$ & $*$ & $*$ & - & - & - \\
\hline Leuco Crystal Violet & Blood & $* *$ & $* *$ & $* *$ & $* *$ & $*$ & $*$ \\
\hline Leuco Rhodamine 6G & Blood & $* *$ & $* *$ & $* *$ & $* *$ & $* *$ & $*$ \\
\hline Fluorescein & Blood & $* * *$ & $* * *$ & $* * *$ & - & $* *$ & $* *$ \\
\hline Hemascein $^{\circledR}$ & Blood & $*$ & $*$ & $*$ & $* *$ & - & - \\
\hline Bluestar Forensic Mangum & Blood & $* *$ & $* *$ & $* *$ & $* *$ & $* * *$ & $* * *$ \\
\hline GC Aroma Dust Fine III Alginate & Blood & $* * *$ & $* * *$ & $* * *$ & $* * *$ & $* *$ & $* *$ \\
\hline Titanium Dioxide & Blood & $*$ & $* *$ & - & - & - & - \\
\hline $\mathrm{DFO}$ & Urine & - & - & - & $* * *$ & - & - \\
\hline 1,2-IND & Urine & - & - & - & $* * *$ & - & - \\
\hline DMAC & Urine & - & - & - & $* * *$ & - & - \\
\hline Ninhydrin & Urine & - & - & - & $*$ & - & - \\
\hline Potassium Thiocyanate & Soil & - & $*$ & - & $* *$ & $*$ & $*$ \\
\hline Potassium Ferrocyanide & Soil & - & $*$ & - & $* *$ & $*$ & $*$ \\
\hline $\begin{array}{l}\text { Ammonium } \\
\text { Pyrrolidinedithiocarbamate }\end{array}$ & Soil & - & - & - & $* * *$ & $*$ & $*$ \\
\hline 2,2'-Dipyridil & Soil & $*$ & $*$ & $*$ & $* * *$ & $*$ & $*$ \\
\hline
\end{tabular}




\section{References}

1. Warrick P. Identification of blood prints on fabric using amido black and digital enhancement. J Forensic Ident 2000;50(1):20-32.

2. Zauner DR. Friction ridge impression in blood on blue denim. J Forensic Ident 1998;48(6):689-91.

3. Keith LV. Footwear impression on fabric. J Forensic Ident 2002;52(6):681-5.

4. Springer E, Almog J, Frank A, Ziv Z, Bergman P, Gui Qiang W. Detection of dry body fluids by inherent short wavelength UV luminescence: preliminary results. Forensic Sci Int 1994;66(2):89-94.

5. Shor Y, Vinokurov A, Glattstein B. The use of an adhesive lifter and $\mathrm{pH}$ indicator for the removal and enhancement of shoeprints in dust. J Forensic Sci 1998;43(1):182-4.

6. Shor Y, Tsach T, Vinokurov A, Glattstein B, Landau E, Levin N. Lifting shoeprints using gelatin lifters and a hydraulic press. J Forensic Sci 2003;48(2):368-72.

7. Adair T. Casting Two-dimensional bloody shoe prints from concrete, fabric and human skin: a review of several methods. IABPA News 2005 March:4-8.

8. Shor Y, Tsach T, Wiesner S, Meir G. Removing interfering contaminants from gelatin lifters. J Forensic Sci 2005;50(6):1386-93.

9. Brooke H, Baranowski MR, McCutcheon JN, Morgan SL, Myrick ML. Multimode imaging in the thermal infrared for chemical contrast enhancement. Part 3: visualizing blood on fabrics. Anal Chem 2010;82(20):8427-31.

10. Farrugia KJ, Nic Daéid N, Savage KA, Bandey HL. Chemical enhancement of footwear impressions in blood deposited on fabric - evaluating the use of alginate casting materials followed by chemical enhancement. Sci Justice 2010;50(4):200-4.

11. Farrugia KJ, Savage KA, Bandey HL, Nic Daéid N. Chemical enhancement of footwear Impressions in blood on fabric - part 1: protein stains. Sci Justice 2011;51(3):99-109. 
12. Farrugia KJ, Savage KA, Bandey HL, Ciuksza T, Nic Daéid N. Chemical enhancement of footwear impressions in blood on fabric - part 2: peroxidase reagents. Sci Justice 2011;51(3):110-21.

13. Farrugia KJ, Bandey HL, Bleay S, Nic Daéid N. Chemical enhancement of footwear impressions in urine on fabric. Forensic Sci Int 2012;214(1-3):67-81.

14. Farrugia KJ, Bandey H, Dawson L, Nic Daéid N. Chemical enhancement of soil based footwear impressions on fabric. Forensic Sci Int 2012;219(1-3):12-28.

15. Fraser J, Sturrock K, Deacon P, Bleay S, Bremner DH. Visualisation of fingermarks and grab impressions on fabrics. Part 1: gold/zinc vacuum metal deposition. Forensic Sci Int 2011;208(1-3):74-8.

16. Morgan-Smith RK, Elliot DA, Adam H. Enhancement of aged shoeprints in blood. J Forensic Ident 2009;59(1):45-50.

17. Theeuwen ABE, van Barnevald S, Drok JW, Keereweer I, Lesger B, Limborgh JCM, et al. Enhancement of muddy footwear impressions. Forensic Sci Int 2001;119(1):57-67.

18. Theeuwen ABE, van Barneveld S, Drok JW, Keereweer I, Limborgh JCM, Naber WM, et al. Enhancement of footwear impressions in blood. Forensic Sci Int 1998;95(2):133-51.

19. Bandey HL. Special Edition: Footwear mark recovery. HOSDB Publication May 2008; 24/08.

20. James SH, Kish PE, Sutton TP. Principles of bloodstain pattern analysis: theory and practice. 3rd rev ed. FL: CRC Taylor and Francis Group LLC, 2005.

21. Velders MJM, editor. Fluorescing traces in blood on white gelatin lifters with hungarian red. Proceedings of the 81st Educational Conference of the International Association of Identification; 1996; Greensboro, NC.

22. Sears VG, Butcher CPG, Fitzgerald LA. Enhancement of Fingerprints in blood - part 3: reactive techniques, acid yellow 7, and process sequences. J Forensic Ident 2005;55(6):74163.

23. Becue A, Moret S, Champod C, Margot P. Use of Quantum dots in aqueous solution to detect blood fingermarks on non-porous surfaces. Forensic Sci Int 2009;191(1):36-41. 
24. Agarwal M, Herlihy R, Reitnauer A. A comparative study of the development of blood impressions on dark-coloured substrates using phloxine B and and acid yellow 7. Fingerprint Whorld 2010;36(140):98-111.

25. Bouwmeester M, Gorré S, Rodriguez C, De Puit M. A comparison of reagents for the visualisation of blood prints on knives with black handles. J Forensic Ident 2011;61(4):35362.

26. Bodziak WJ. Use of leuco crystal violet to enhance shoe prints in blood. Forensic Sci Int $1996 ; 82(1): 45-52$.

27. Becue A, Moret S, Champod C, Margot P. Use of stains to detect fingermarks. Biotech Histochem 2010;86(3):140-60.

28. Bossers LCAM, Roux C, Bell M, McDonagh AM. Methods for the enhancement of fingermarks in blood. Forensic Sci Int 2011;210(1-3):1-11.

29. Cheeseman R, DiMeo LA. Fluorescein as a field-worthy latent bloodstain detection system. J Forensic Ident 1995;45(6):631-46.

30. Dilbeck L. Use of Bluestar Forensic in lieu of luminol at crime scenes. J Forensic Ident 2006;56(5):706-29.

31. Yapping L, Yue W. Blood Latent fingerprint detection using LeuR6G. J Forensic Ident 2004;54(5):542-46

32. Frégeau CJ, Germain O, Fourney RM. Fingerprint enhancement revisited and the effects of blood enhancement chemicals on subsequent profiler Plus ${ }^{\mathrm{TM}}$ fluorescent short tandem repeat DNA analysis of fresh and aged bloody fingerprints. J Forensic Sci 2000;45(2):354-80.

33. Sahs PT. DAB: An advancement in blood print detection. J Forensic Ident 1992;42(5):412-20.

34. Bergeron J. Development of bloody prints on dark surfaces with titanium dioxide and methanol. J Forensic Ident 2003;53(2):149-61.

35. Inoue K, Song YX, Fujii K, Kadokawa A, Kanie T. Consistency of alginate impression materials and their evaluation. J Oral Rehabil 1999;26(3):203-7. 
36. Wiesner S, Izraeli ES, Shor Y, editors. Lifting and enhancing bloody footwear impression on clothing. European Meeting for SP/TM Examiners; 2007 29-31 May 2007; Copenhagen: Denmark.

37. Froude $\mathrm{JH}$. Using ammonium thiocyanate and potassium thiocyanate. J Forensic Ident 1998;48(6):718-24.

38. Brundage DJ. Ammonium thiocyanate: a successful technique for dusty footwear impressions. Proceedings of the International Symposium on the Forensic Aspects of Footwear and Tire Impression Evidence; 1994; Quantico, VA. FBI Academy.

39. Glattstein B, Shor Y, Levin N, Zeichner A. $\mathrm{pH}$ indicators as chemical reagents for the enhancement of footwear marks. J Forensic Sci 1996;41(1):23-6.

40. Someha S. Chemical techniques for the enhancement of footwear and tire impressions in Japan. Proceedings of the International Symposium on the Forensic Aspects of Footwear and Tire Impression Evidence; 1994; Quantico, VA. FBI Academy.

41. Bannister M. The use of ultra-violet imaging in the detection of forensic evidence [MSc dissertation]. Bath (UK): University of Bath, 2009.

42. Farrugia KJ, Nic Daéid N, Savage KA, Riches P, Bandey HL. Controlling the variable of pressure in the production of test footwear impressions. Sci Justice. In press (DOI: 10.1016/j.scijus.2011.11.002).

43. Bowman V, editor. Manual of fingerprint development techniques. $2^{\text {nd }}$ rev. edn. Sandridge, UK: Police Scientific Development Branch, Home Office, 2005.

44. Lee JL, Bleay S, Sears VG, Mehmet S, Croxton R. Evaluation of the dimethylaminocinnamaldeyhde contact transfer process and its application to fingerprint development on thermal papers. J Forensic Ident 2009;59(5):545-68.

45. Yamashita B, French M. Latent Print Development. In: SWGFAST, editor. The Fingerprint Sourcebook: The National Institute of Justice; September 2010.

46. Spence L, Asmussen G. Spectral enhancement of leucocrystal violet treated footwear impression evidence in blood. Forensic Sci Int 2003;137(2):117-24. 
47. Budowle B, Leggitt JL, Defanbaugh DA, Keys KM, Malkiewicz SF. The presumptive reagent fluorescein for the detection of dilute bloodstains and subsequent STR typing of recovered DNA. J Forensic Sci 2000;45(5):1090-2.

48. Powell L. Enhancing footwear marks made in blood [MSci dissertation]. Glasgow (UK): University of Strathclyde, 2008.

49. Zarate J, Morden C. Fluorogenic method for lifting, enhancing and preserving bloody impression evidence. J Forensic Ident 2011;61(3):260-80

Additional information and reprint requests:

Professor Niamh Nic Daéid Ph.D.

Centre for Forensic Science

WestCHEM, Department of Pure and Applied Chemistry

University of Strathclyde

Glasgow G1 1XW

U.K.

Email:n.nicdaeid@strath.ac.uk 